Board of Governors of the Federal Reserve System

International Finance Discussion Papers

Number 584

June 1997

\title{
THE BANK LENDING CHANNEL OF MONETARY POLICY TRANSMISSION: EVIDENCE FROM A MODEL OF BANK BEHAVIOR THAT INCORPORATES LONG-TERM CUSTOMER RELATIONSHIPS
}

\author{
Michael S. Gibson
}

NOTE: International Finance Discussion Papers are preliminary materials circulated to stimulate discussion and critical comment. References to International Finance Discussion Papers (other than an acknowledgment that the writer has had access to unpublished material) should be cleared with the author or authors. Recent IFDPs are available on the Web at www.bog.frb.fed.us. 


\title{
THE BANK LENDING CHANNEL OF MONETARY POLICY TRANSMISSION: EVIDENCE FROM A MODEL OF BANK BEHAVIOR THAT INCORPORATES LONG-TERM CUSTOMER RELATIONSHIPS
}

\author{
Michael S. Gibson*
}

\begin{abstract}
I test for the existence of a bank lending channel of monetary policy transmission. I identify bank lending channel effects with a simple model of bank behavior incorporating longterm customer relationships. The model suggests that when a large fraction of bank assets is held in loans, contractionary monetary policy shocks are more likely to cause a cutback in bank lending, in turn reducing real economic activity. This implication of the model is supported in the data. I conduct a "horse race" between the bank lending channel and two alternative non-usercost-of-capital channels of monetary transmission. The bank lending channel is the strongest of the three. The ability of the fraction of bank assets held in loans to predict how the strength of monetary policy transmission varies over time should be of interest to both theorists and forecasters of business cycles.
\end{abstract}

Keywords: monetary policy transmission, bank lending, customer relationships

*Internet: gibsonm@frb.gov. I thank Anil Kashyap, Don Morgan, and participants in the October 31,1996 System Committee on Macroeconomics meeting and the International Finance Seminar at the Federal Reserve Board for helpful comments. I thank Don Morgan for suggesting Figure 4. The author is an economist in the Division of International Finance, Board of Governors of the Federal Reserve System. This paper represents the views of the author and should not be interpreted as reflecting the views of the Board of Governors of the Federal Reserve System or other members of its staff. 


\section{Introduction}

Do banks contribute to the transmission of monetary policy? Some economists argue that banks transmit monetary policy to the real economy, some argue that monetary policy transmission depends on the financial conditions of firms and households but not on banks, and some argue that traditional effects of monetary policy on the user cost of capital explain how monetary policy impacts the real economy.

I model bank lending behavior in a world where long-term customer relationships matter. The model characterizes the response of bank lending to monetary policy shocks. ${ }^{1}$ The model suggests a test for the strength of the "bank lending channel" of monetary policy. Also, the model provides an explanation for why monetary policy can have large effects at some times and small effects at other times - because the strength of the bank lending channel varies over time.

Using data on real GDP and bank balance sheets over 1960-95, I test for the existence of a bank lending channel. I control for the potential existence of other non-user-cost-of-capital channels, essentially running a "horse race" to see which channels can best explain the response of GDP to monetary policy. The results suggest that, at times, bank lending plays a powerful role in transmitting monetary policy shocks to the real economy. That the strength of the transmission mechanism varies with an observable variable (the composition of bank balance sheets) is a fact that appears to have been underappreciated by forecasters and theorists of the business cycle alike.

\section{Previous evidence on monetary policy transmission}

One can broadly distinguish between two ways monetary policy affects the economy: through the user cost of capital, and through other financial market mechanisms. Because the higher interest rates that result from a monetary tightening raise the user cost of capital for firms and consumers, spending on investment and consumer durables declines. The existence of the "user cost of capital channel" is not in dispute, although its importance is (compare Taylor (1995) and Bernanke and Gertler (1995)). The existence and importance of other financial market channels are in dispute. One of these financial market channels, the bank lending channel, is the subject of this paper.

\footnotetext{
${ }^{1}$ To justify a link between bank lending and real economic activity, I rely on the existing literature on that subject, surveyed in Kashyap and Stein (1994).
} 


\subsection{Financial market channels of monetary transmission}

Among the financial market channels, at least three related to credit can be distinguished. ${ }^{2}$ A bank lending channel refers to the following chain of causality: monetary policy is tightened, bank reserves fall, bank liabilities decline because the decline in transactions deposits caused by the decline in reserves cannot be costlessly offset, bank assets decline, some of the decline in assets is reflected in a decline in loans, and, finally, because of the decline in the supply of bank loans, real output falls.

Two other channels related to the cost and availability of credit are the "net worth channel" and the "internal funds channel." Oliner and Rudebusch $(1995,1996)$ lump them together as the "broad credit channel." These channels focus on the financial conditions of firms and consumers, rather than financial intermediaries. According to the "net worth channel," when monetary policy is tightened, higher interest rates reduce the net worth of firms and consumers by reducing the value of fixed assets (i.e. land). Lower net worth reduces the ability of firms and consumers to borrow to finance fixed and inventory investment. In the "internal funds channel," when monetary policy is tightened and interest rates rise, firms' and consumers' interest payments on floating rate debt rise, thus their cash flow (net of interest payments) declines. Investment falls because, for some firms at least, external funds are unavailable or are more costly than internal funds.

\subsection{Previous literature on the bank lending channel}

The early literature on the importance of bank credit for macroeconomic fluctuations looked at the forecasting power of bank credit for economic activity in a vector autoregression (VAR) framework (King 1986). However, tests of the forecasting power of credit aggregates in a VAR with aggregate data do not tell us anything about the underlying channels of monetary transmission, as Bernanke and Gertler (1995) made clear. In light of the inadequacy of unconstrained VARs estimated with aggregate data, two approaches have been pursued to identify monetary policy effects that are transmitted through bank credit: either impose more structure on the relationships between aggregate variables, or use micro data and exploit heterogeneity among individual agents.

Kashyap, Stein, and Wilcox (1993) followed the first strategy by looking at firms' financing mix between bank loans and commercial paper. To achieve identification, they assumed changes

\footnotetext{
${ }^{2}$ Fazzari (1995) discusses these three. Mishkin (1996) identifies these three credit-related channels and half a dozen more not linked to credit.
} 
in credit demand do not shift the financing mix, while changes in the relative supply of bank loans and commercial paper do. They found that the financing mix shifts away from bank loans after a monetary policy contraction, and the financing mix helps predict movements in inventories and equipment investment. These two findings together support the existence of a bank lending channel.

However, Oliner and Rudebusch (1995) claim that the Kashyap, Stein, and Wilcox result is spurious, because the credit demand of bank-dependent firms falls relative to that of non-bankdependent firms after a monetary policy shock. In this interpretation, the Kashyap, Stein and Wilcox identification assumption is invalid, since changes in the financing mix reflect credit demand as well as credit supply. To support their interpretation, Oliner and Rudebusch show that, looking at only small firms or only large firms, the financing mix between bank loans and other short-term debt does not respond to a monetary policy shock. ${ }^{3}$ The financing mix for all firms responds to an aggregate shock because, after a monetary policy shock, small firms get less credit from all sources, and large firms get more. To explain why the credit demand of small and large firms moves in opposite directions after a monetary policy shock, Oliner and Rudebusch rely on a broad credit channel. ${ }^{4}$

Gertler and Gilchrist (1994) follow the second strategy, achieving identification through disaggregated data on various size classes of manufacturing firms. They estimate the response of small and large firms to monetary policy shocks and find that sales and inventories fall at small firms by more than at large firms after a monetary contraction, which they interpret as evidence of a credit channel of monetary transmission. They appeal to both the bank lending channel and the broad credit channel to motivate their empirical work.

Obviously, there are many ways in which small and large firms differ apart from financial factors, which cloud the interpretation of the Gertler and Gilchrist (1994) results. While size is certainly correlated with access to non-bank sources of credit, the correlation is far from perfect. ${ }^{5}$ Worse, size is likely to be correlated with other factors that would affect a firm's response to a monetary tightening. To address these criticisms, Gilchrist and Zakrajšek (1995) assumed high-leverage

\footnotetext{
${ }^{3}$ Kashyap, Stein and Wilcox (1996) show that, looking only at large firms, the financing mix between bank loans and commercial paper does respond to a monetary policy shock. It is not clear why the two definitions of the financing mix give different results.

${ }^{4}$ Gertler and Gilchrist (1994) also rely on the differential response of small and large firms to a monetary policy contraction as evidence in favor of a broad credit channel.

${ }^{5}$ Gibson (forthcoming) tests whether the health of a Japanese firm's main bank affects its investment behavior. He directly measures a firm's dependence on bank credit (by observing whether the firm has ever issued bonds) and finds that bank health affects investment at bank-dependent firms. When firms are sorted by size instead of bank-dependence, the effect of bank health diminishes and is no longer statistically significant.
} 
firms were more likely to be credit constrained and split firms into four quartiles based on leverage. They found that the effect of cash flow on inventory investment was monotonically increasing with leverage across the four quantiles. Still, leverage also has problems as a proxy for the likelihood a firm is credit constrained. The corporate finance literature has identified many reasons why leverage varies that could be correlated with other real factors affecting a firm's response to monetary policy shocks (for example, profitability or degree of tangibility of assets). ${ }^{6}$ Worthington (1995) shows that tangibility of assets affects the responsiveness of cash flow to investment, which complicates the interpretation of Gilchrist and Zakrajšek's (1995) empirical work.

Although Gertler and Gilchrist (1994) appeal to both a bank lending channel and a broad credit channel, their empirical work is more consistent with the latter. If one wanted to use firm-level data to study the bank lending channel, one would need to identify firms who are cut off from bank credit following a monetary tightening. Instead, Gertler and Gilchrist (1994) separate out firms that are small. It seems plausible to argue that a bank would earn lower profit on a loan to a large firm with access to public capital markets than on a loan to a small firm where it may have some monopoly power as an insider with more information than other potential lenders. A profit-maximizing bank may have an incentive to reduce lending to large firms, not small firms, after a monetary contraction. Absent some direct evidence on which firms truly are rationed by banks following a monetary contraction, this logic suggests that firm size may be a better proxy for broad credit channel effects than for bank lending channel effects.

Also following the second strategy, Kashyap and Stein (1995) use micro data on bank balance sheets to identify effects of monetary policy on bank lending. They divide banks into size categories and look at the response of lending to monetary policy shocks, which they identify as changes in the federal funds rate. They find that bank lending declines after a monetary policy contraction at all but the largest banks. They interpret this as evidence supporting the existence of a bank lending channel, since one of the links in the chain of causality behind the bank lending channel is that after a monetary policy contraction, banks lend less. However, their result is also consistent with a fall in credit demand of small bank borrowers relative to large bank borrowers (consistent with the Oliner and Rudebusch (1995) criticism of Kashyap, Stein, and Wilcox (1993)). Kashyap and Stein (1995) do not look at the next step in the chain of causality to see whether the differential

\footnotetext{
${ }^{6}$ Rajan and Zingales (1995) find that "leverage generally increases with the proportion of tangible assets and the size of the company, decreases with the market to book, the return on assets, and the presence of nondebt tax shields."
} 
response of small and large banks to monetary policy has an effect on the real economy.

In this paper I follow the first strategy: I use aggregate data and impose some structure on the relationship between monetary policy shocks, bank lending, and GDP. I derive a simple model of bank behavior in the presence of customer relationships - the model implies that monetary policy will be transmitted through bank lending at some times, but not at others. I test to see whether the effect of monetary policy shocks on GDP is nonlinear as the model suggests. If so, I will interpret that as evidence that banks do play a role in transmitting monetary policy shocks to the real economy.

\subsection{Other research on monetary policy transmission}

Other researchers have undertaken analyses similar to mine, allowing the effect of a monetary policy shock on output to depend on outside factors. Examples include whether the shock is contractionary or expansionary (Ammer and Brunner 1995, Cover 1992, Morgan 1993), whether the economy is expanding or contracting (Ammer and Brunner 1995), or whether the economy is in a "credit crunch" (McCallum 1991). Some of these researchers have identified monetary policy shocks in ways that today would not be considered "state of the art." For example, as Ammer and Brunner (1995) and Morgan (1993) point out, Cover's (1992) methodology does not distinguish between true monetary policy shocks and other movements in money, e.g. due to money demand shocks. McCallum's (1991) methodology is subject to the same criticism.

Ammer and Brunner (1995) estimated univariate regressions of output on lagged output and monetary policy shocks, allowing monetary policy shocks to have asymmetric effects depending on, first, whether the shock was expansionary or contractionary, and, second, whether the economy was in an expansion or recession. They found that only the first asymmetry mattered, which they view as evidence against a credit channel of monetary policy transmission. They argue that existing theories of the credit channel imply that "monetary policy shocks should be more effective during recessions, when large numbers of households and firms are likely to be credit-constrained" (Ammer and Brunner 1995, p. 1). ${ }^{7}$ For a broad credit channel, where the financial condition of borrowers is most important, the implication is correct. But the same cannot be said of the bank lending channel.

The model I present below has no such implication. Its implications for monetary policy trans-

\footnotetext{
${ }^{7}$ This view is explicitly stated in Gertler and Gilchrist (1994), p. 314 and n. 31 on p. 331.
} 
mission have nothing to do with the state of the economy and everything to do with bank lending behavior. By modeling bank lending behavior, I show explicitly how monetary policy shocks affect bank lending and, through bank lending, the real economy. The disadvantage of my approach is that my test of the importance of the bank lending channel of monetary policy transmission is really a joint test of the bank lending channel and of my model of bank behavior. If my model omits an important relationship, my empirical test will be misspecified.

\section{A model of bank lending with customer relationships}

\subsection{The importance of customer relationships}

Recent literature has pointed to the importance of bank customer relationships for both large and small firms. Lummer and McConnell (1989) found that announcements of renewals of bank lines of credit are associated with positive excess stock market returns, while announcements of new lines of credit are not, suggesting that a bank's decision to continue a customer relationship gives the market a positive signal about the firm's future profitability. Slovin, Sushka, and Polonchek (1993) examined excess stock market returns for firms that had a relationship with Continental Illinois Bank around the time of its rescue by the FDIC. Before the FDIC took over Continental Illinois, when their banking relationships were in jeopardy, these firms had negative excess stock returns. After the takeover, which preserved their valuable relationships with Continental Illinois, these firms had positive excess stock returns. These two studies demonstrate that bank relationships are valuable to large, stock-market-listed firms.

Petersen and Rajan (1994) examine the price and availability of credit to small businesses. They find that a bank relationship increases the availability of credit but has no effect on the price. Berger and Udell (1995), using the same dataset but only loans made under a line of credit, find that small firms with longer bank relationships borrow at lower interest rates and post less collateral. Both studies suggest that customer relationships are also important to small firms.

Based on the above evidence that long-term relationships between banks and firms are an important feature of U.S. credit markets, I incorporate customer relationships into a simple model of bank portfolio choice. Customer relationships will be modeled in a simple and tractable way, by assuming it is more costly for a bank to lend to a new customer than an existing customer. Although the model's structure is quite simple, it has strong implications for the transmission of 
monetary policy shocks through bank lending.

\subsection{Definitions}

At time $t$, the bank has $c(t)$ loan customers, with an average loan size of $\lambda(t)$. The size of the bank's loan portfolio $c(t) \lambda(t)$ must always be less than its total assets $A(t)$. Let $z(t)$ be the ratio of loans to assets,

$$
z(t) \equiv \frac{c(t) \lambda(t)}{A(t)}
$$

The bank holds all assets not lent to firms in securities, so its securities portfolio equals $A(t)[1-z(t)]$. The bank faces uncertainty in the average loan size $\lambda(t)$ and total assets $A(t)$. Let $\lambda(t)$ and $A(t)$ be geometric Brownian motions with parameters $\left(\mu_{\lambda}, \sigma_{\lambda}\right)$ and $\left(\mu_{A}, \sigma_{A}\right)$ respectively. These two variables move randomly, beyond the bank's control. The bank can only control $z(t)$ by varying the number of loan customers, $c(t)$.

The laws of motion for $c(t), \lambda(t)$ and $A(t)$ are assumed to be:

$$
\begin{aligned}
\frac{\mathrm{d} c(t)}{\mathrm{d} t} & =-\delta c(t) \\
\frac{\mathrm{d} \lambda(t)}{\lambda(t)} & =\mu_{\lambda} \mathrm{d} t+\sigma_{\lambda} \mathrm{d} w_{\lambda}(t) \\
\frac{\mathrm{d} A(t)}{A(t)} & =\mu_{A} \mathrm{~d} t+\sigma_{A} \mathrm{~d} w_{A}(t)
\end{aligned}
$$

where $w_{\lambda}(t)$ and $w_{A}(t)$ are Wiener processes with correlation $\phi$. Use Ito's lemma and equation (1) to calculate the law of motion of $z(t)$ when no customers are added or dropped:

$$
\begin{aligned}
\frac{\mathrm{d} z(t)}{z(t)} & =\mu_{z} \mathrm{~d} t+\sigma_{z} \mathrm{~d} w_{z}(t), \\
\text { where } \mu_{z} & =-\delta+\mu_{\lambda}-\mu_{A}-\sigma_{\lambda} \sigma_{A} \phi+\sigma_{A}^{2} \\
\sigma_{z} & =\left(\sigma_{\lambda}^{2}+\sigma_{A}^{2}-2 \phi \sigma_{\lambda} \sigma_{A}\right)^{1 / 2}
\end{aligned}
$$

and $w_{z}(t)$ is a Wiener process. 


\subsection{How reasonable are the model's assumptions?}

\subsubsection{Average loan size varies beyond the bank's control}

If a sizable fraction of a bank's loans is made under loan commitments or lines of credit, average loan size will be subject to shocks that are beyond the bank's control. The size of loans made under commitment will vary beyond the bank's control and the size of non-commitment loans will stay constant until repaid. According to the Federal Reserve's Survey of Terms of Bank Lending to Business, 66 percent of short-term commercial and industrial (C\&I) loans and 79 percent of long-term C\&I loans made during February 5-9, 1996, were made under a loan commitment. ${ }^{8}$ Morgan (forthcoming) found that the fraction of bank loans made under commitment rose when monetary policy was tightened. As a result, the assumption that average loan size varies beyond the bank's control appears quite reasonable.

\subsubsection{The bank controls the number of loan customers}

I assume the bank can increase or decrease $c(t)$ at any time. The bank can decrease $c(t)$ by simply dropping a customer. To be able to increase $c(t)$ at any time, the bank must be able to find a willing borrower in booms and in slumps. For this condition to always be satisfied, there must always be some firms who would like to borrow more at current interest rates, if banks were willing to lend more. This is a maintained hypothesis of much of the literature on the effects of financial factors on firm behavior, and I maintain the hypothesis here.

I assume a constant separation rate of $\delta$, representing borrowers who exogenously sever their relationship with the bank, e.g. because the firm goes out of business.

\subsubsection{Total assets fluctuate beyond the bank's control}

I assume $A(t)$ is random and cannot be adjusted by the bank. This is a strong assumption, because it rules out active liability management, where a bank lends money first and then incurs a liability (sells large CDs, borrows federal funds or Eurodollars) to keep its balance sheet balanced. Although the assumption is overly strong, it contains a kernel of truth, since there are exogenous shocks to which banks respond by changing the size of their assets. Kashyap and Stein (1995) identified two such shocks: core deposit shocks and monetary policy shocks. Kashyap and Stein (1995) refuted the

\footnotetext{
${ }^{8}$ Federal Reserve Statistical Release E.2, March 13, 1996.
} 
argument of Romer and Romer (1990) that liability management shuts off any effect of monetary policy on the size of bank balance sheets.

The assumption that $A(t)$ cannot be controlled by the bank simplifies the analysis by limiting the variables under the bank's control to one: the number of loan customers. This forces a bank to make all its adjustments by adding or dropping customers. If the model were generalized to allow the bank to have some control, at some cost, over $A(t)$ and $\lambda(t)$, the model would be less tractable. However, the model's prediction for monetary policy transmission through bank lending would be qualitatively unchanged.

\subsection{The bank's objective function}

The bank's decision problem at time $t$ is

$$
\begin{gathered}
\max _{\{c(s): s=t, \ldots, \infty\}} \mathrm{E}_{t}\left[\int_{t}^{\infty} e^{-\rho(s-t)} f(z(s)) \mathrm{d} s-\Gamma\right] \\
\text { subject to } 0 \leq z(s) \leq 1, \forall s
\end{gathered}
$$

and (2), the law of motion for $z(t)$,

where $\rho$ is the bank's discount rate, $f(z)$ is the bank's profit from putting a fraction $z$ of its assets into loans, and $\Gamma$ is the cumulative cost of adding customers. I assume $f^{\prime}(0)>0, f^{\prime}(1)<0, f^{\prime \prime}<0$, which is consistent with assuming that loans pay a higher interest rate than securities but that securities are less liquid than loans. Think of $f(z)$ as

$$
f(z)=i_{L} z+i_{S}(1-z)-\psi(z)
$$

where $i_{L}$ and $i_{S}$ are interest rate spreads earned on loans and securities and $\psi(z)$ is a weakly increasing, positive function representing the expected cost of illiquidity. As $z$ rises, the bank's assets become less liquid and the chance of costly illiquidity rises. Define the interior maximum $z^{*}$ by $f^{\prime}\left(z^{*}\right)=0$. At $z^{*}$, the marginal benefit of making an additional loan $\left(i_{L}-i_{S}\right)$ is offset by the marginal cost of illiquidity risk $\left(\psi^{\prime}(z)\right)$. Figure 1 sketches what $f(z)$ should look like. 
Figure 1: What $f(z)$ should look like

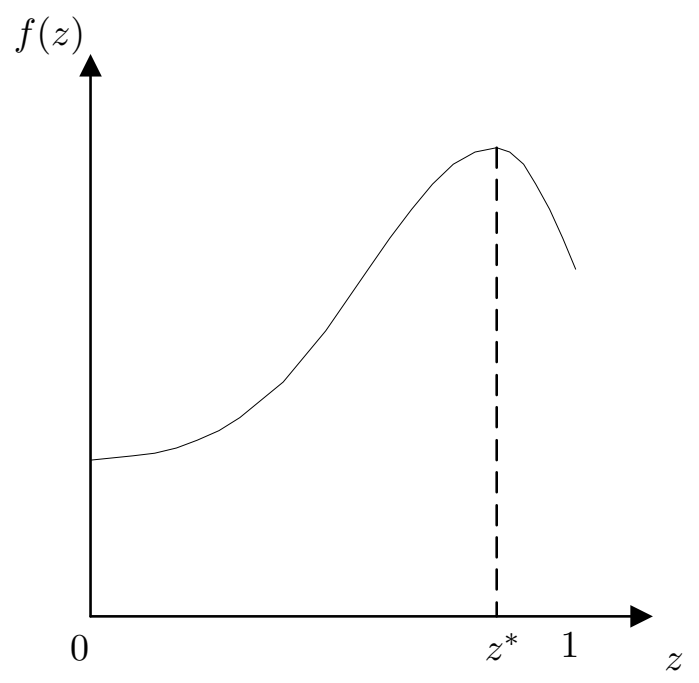

By assuming that the profit function remains constant over time, I am implicitly assuming that the spreads between loan rates, bond rates, and cost of funds also remain constant. ${ }^{9}$ Although assuming interest rate spreads play no part in a bank's portfolio allocation makes the model less realistic, I consider it to be an acceptable simplification, for three reasons. First, theoretical models of credit rationing suggest interest rates will not move to clear credit markets. Lenders cannot raise interest rates without affecting the quality of their loan portfolio. Second, if you ask bankers how they deal with excess demand for loans, they do not say that they raise interest rates until supply equals demand. They control loan volume by tightening collateral or compensating balance requirements but rarely by changing interest rates or loan maturities. The second point is undoubtedly related to the first; bankers understood long before economists proved it formally that using interest rates to clear the market for loans is not optimal behavior. Third, since many loans are granted under loan commitments, which specify interest rate spreads in advance for the duration of the commitment, bankers have less scope than one might think for changing rates at the business cycle frequency.

\footnotetext{
${ }^{9} \mathrm{I}$ am also assuming liquidity needs (the function $\psi$ ) and default risk are constant.
} 


\subsection{Add long-term customer relationships}

I have not yet added long-term relationships between banks and their loan customers to the model. I will make a crude simplification of the effects of asymmetric information on bank behavior: assume the bank must pay a cost $\gamma$ any time it adds a new loan customer. Customers can be dropped costlessly. Adding this friction to the bank's decision problem will affect bank behavior.

Without the cost $\gamma$ of adding a new loan customer, the bank's optimal policy would be simple: keep $z(t)=z^{*}$ at all times. With the cost of adjustment $\gamma$, the bank's problem falls into the class of regulated Brownian motion problems studied by Harrison (1985) and Dumas (1989). Economists have used this mathematical technique to study inventories, labor demand, entry and exit decisions and irreversible investment. ${ }^{10}$ Solving the problem (3) with the transaction cost $\gamma$, the bank's optimal policy is to let $z(t)$ fluctuate freely between some bounds $u$ and $\ell$ and to control $z(t)$ by adding or subtracting customers when it hits the bounds. ${ }^{11}$ Figure 2 displays the optimal policy for a randomly generated $z(t)$.

The bank chooses $u$ and $\ell$ optimally. The bank's choice of $u$ and $\ell$ will depend on the parameters of the model; a derivation of the optimal $u$ and $\ell$ is given in the mathematical appendix. Intuitively, a larger $\gamma$ will cause $u$ to rise and $\ell$ to fall, because the bank will wait longer to add and drop new customers if the cost of adding customers is higher.

\subsection{A description of optimal behavior}

Adding a linear transaction cost to the agent's decision problem causes the agent to adjust infrequently. As $\lambda(t)$ and $A(t)$ fluctuate, moving $z(t)$ around inside its band, the bank does not add or drop customers. When loan demand from established customers increases, the bank grants the credit. When total assets go up, the bank puts the increment into securities until it is able to lend it out. Within the band, the bank meets credit demands of established customers but does not grant loans to any new customers. When a shock pushes $z(t)$ below $\ell$, the bank adds customers by approving loan applications of new borrowers. When a shock pushes $z(t)$ above $u$, the bank drops customers. I assume the relationship between a firm and a bank must be continuously maintained for the firm to remain an "insider" borrower. ${ }^{12}$ The bank retains no knowledge of the business of

\footnotetext{
${ }^{10}$ See Constantinides and Richard (1978), Bentolila and Bertola (1990), Dixit (1989) and Bertola (1988).

${ }^{11} \mathrm{~A}$ more complete solution of (3) is given in the mathematical appendix.

${ }^{12}$ If banks retained knowledge of dropped customers, little would change in the model. Banks could costlessly choose $c(t) \in[0, K(t)]$, where $K(t)$ is the number of customers of whose business the bank has current or recent
} 
Figure 2: A sample path for $z(t)$, assuming the bank follows the policy $u=.72$ and $l=.65$.

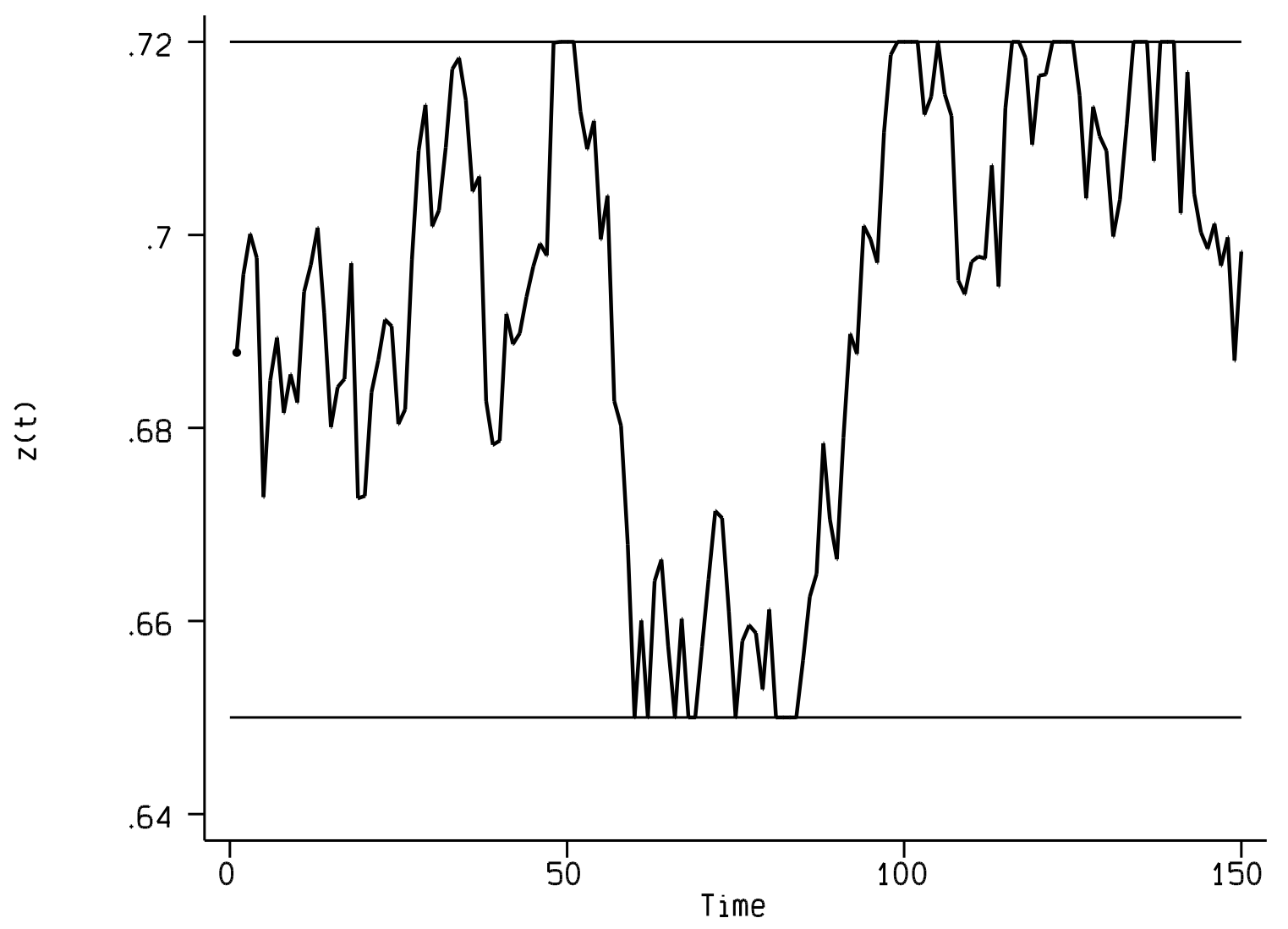


a dropped customer. ${ }^{13}$

\section{Implications for monetary policy transmission}

Monetary policy shocks enter the model in two ways. First, a contractionary monetary policy shock will reduce the assets banks have available to lend out, and an expansionary shock will increase those assets. Obviously this link is a product of the adjustments of banks and depositors along many margins, but it appears to be robust in the data (Kashyap and Stein 1995). Second, a contractionary monetary policy shock will affect loan demand, and thus average loan size. Loan demand will fall if the contractionary shock leads borrowers to borrow less because they spend less, in anticipation of a future slowdown in economic activity. But, loan demand will rise if borrowers suffer an unanticipated shortage of cash or unanticipated increase in inventories as a result of the monetary policy contraction. Bernanke and Blinder (1992) showed that loans rise and then fall after a monetary policy shock; Eichenbaum (1994) showed the same pattern for large and small firms separately. These results suggest that the initial impact of a monetary policy contraction on loan demand is positive. ${ }^{14}$ These two effects combine to ensure that a monetary contraction will result in a positive shock to $z(t)$, and vice versa for a monetary expansion.

The transmission of monetary policy through bank lending will depend on where $z(t)$ is within its band. When $z(t)$ is in the interior of its band, there will not be a strong link between monetary policy shocks and bank lending, because the optimal response of a bank is to do nothing and avoid the cost of adding or dropping a customer. The transmission of such a monetary policy shock to the real economy will take place through other channels.

When $z(t)$ is at its upper bound, a contractionary monetary policy shock will tend to push $z(t)$ above its upper bound. The bank's response will be to reduce its lending by dropping customers. As a result, the spending of bank-dependent firms and households will fall. The bank lending channel will be operating, in addition to other channels, making the effect of monetary policy on the economy stronger than when $z(t)$ is in the interior of its band. Note that there is no transmission

knowledge. $c(t)$ would only be less than $K(t)$ when $z(t)=u$. Once a negative shock hit $z(t)$, the bank would immediately add back old customers to keep $z(t)=u$; as soon as $c(t)=K(t)$ and all old customers were again being served, the usual dynamics would apply again.

${ }^{13}$ In what follows, I will generalize the model of a single bank outlined above to the entire U.S. banking system. In an unpublished working paper, I have derived the conditions under which such an aggregation is valid. Here, I will simply assume that the model can be applied to aggregate data on U.S. commercial banks.

${ }^{14}$ If loans increase, and if the impact of the monetary contraction on loan supply is assumed to be non-positive, loan demand must have increased. 
of expansionary monetary policy shocks through bank lending when $z(t)$ is at its upper bound, because such a shock pushes $z(t)$ back into the interior of its band.

The opposite logic applies when $z(t)$ is at its lower bound. Expansionary shocks tend to push $z(t)$ below its lower bound, and banks expand their lending in response, by investing in new customer relationships. The bank lending channel operates and increases the magnitude of the effect of expansionary monetary policy on the real economy. Contractionary monetary policy will not be amplified by bank lending when $z(t)$ is at its lower bound.

The model's predictions rely on an intuition whose appeal may be broader than the assumptions underlying this particular model of bank behavior. The model predicts that the negative effect of contractionary monetary policy on bank loan supply should be stronger when the fraction of a bank's assets held in loans is high, since that is when the bank is more likely to be looking to shrink its loan portfolio. Similarly, expansionary monetary policy should have a stronger positive effect on bank loan supply when the fraction of a bank's assets held in loans is low, since the bank will be more likely to be seeking out new loans at that time. Although the model predicts a particular relationship between bank balance sheets and the effect of monetary policy, the intuition applies more generally: the bank lending channel can be tested by seeing whether the strength of monetary policy transmission depends on bank balance sheets. ${ }^{15}$

\section{$5 \quad$ Empirical test of the bank lending channel}

The model implies the force of monetary policy transmission through bank lending will depend on the location of $z(t)$ within its band. When $z(t)$ is at its upper bound, contractionary monetary policy shocks will be propagated through bank lending as existing bank customers are cut off from credit. When $z(t)$ is at its lower bound, expansionary shocks will be propagated through an

\footnotetext{
${ }^{15}$ In Stein (1995), asymmetric information between a bank and its investors forces the bank to pay a premium for its uninsured liabilities. A monetary tightening, by contracting aggregate bank reserves, compels the bank to reduce insured deposits (which are subject to reserve requirements) and to finance a greater fraction of its assets from more-expensive uninsured liabilities. When the average cost of its liabilities rises, the bank will reduce its assets. A bank with a larger "buffer stock" of securities will reduce lending by less in response to such a shock, reducing the transmission of the monetary contraction to the real economy. In this way, Stein's model produces a similar relationship between bank balance sheets and the strength of the bank lending channel of monetary policy transmission.

Miron, Romer, and Weil (1994) also argue that the strength of the bank lending channel should depend on bank balance sheets.

Kashyap and Stein (1996) find that lending responds more strongly to monetary policy at banks where the fraction of assets held in loans is high. Like my model, they focus on the fraction of bank assets held in loans; however, they use this variable to explain bank lending behavior rather than real economic activity. Also, they use bank-level micro data rather than aggregate time-series data.
} 
expansion of bank lending as banks add new loan customers. No matter where $z(t)$ is within its band, the traditional user-cost-of-capital channel of monetary policy transmission will still be at work (and should not vary with the composition of bank balance sheets). The model suggests a non-linearity in the monetary policy transmission mechanism. I test this implication of the model. Because the effects of the bank lending channel may have weakened over time, I also look for a structural break in the model.

Previous tests of the bank lending channel, e.g. Kashyap, Stein and Wilcox (1993) and Kashyap and Stein (1995), have been subject to the criticism that effects they identify as driven by bank loan supply actually reflect changes in loan demand. The test in this paper does not suffer from that problem, as long as a bank considers the status of its balance sheet when approving or denying a new loan but a borrower does not care about the bank's balance sheet when it applies for a loan.

\subsection{Identifying monetary policy shocks}

Following Bernanke and Blinder (1992), Brunner (1994), Ammer and Brunner (1995) and others, I identify monetary policy shocks as the residuals from a Fed reaction function treating the federal funds rate as the monetary policy indicator. I define the monetary policy reaction function as

$$
R_{t}=\alpha_{0}+\sum_{j=0}^{N_{i}} \alpha_{1 j} \Delta Y_{t-j}+\sum_{j=0}^{N_{i}} \alpha_{2 j} \Delta P_{t-j}+\sum_{j=1}^{N_{i}} \alpha_{3 j} \Delta M 1_{t-j}+\sum_{j=1}^{N_{i}} \alpha_{4 j} R_{t-j}+\epsilon_{t}^{m p}
$$

where $R$ denotes the federal funds rate, $N_{i}$ is the number of lags included for subperiod $i, \Delta Y$ denotes real GDP growth, $\Delta P$ denotes CPI inflation, $\Delta M 1$ denotes $M 1$ growth, and the residual from the estimated reaction function, $\epsilon^{m p}$, is the monetary policy shock. ${ }^{16}$ (This specification is taken from Ammer and Brunner 1995 and Brunner 1994). Because many researchers have found the coefficients of such a reaction function to vary over time, the reaction function will be estimated separately for the following subperiods: 1959:Q1-1969:Q4, 1970:Q1-1979:Q3, 1979:Q4-1982:Q3, and 1982:Q4-1995:Q4, with lag lengths $N_{i}$ equal to 2,2,1,2, respectively. Implicit in this choice of a Fed reaction function is the identifying assumption that monetary policy responds to changes in GDP and inflation within the quarter, but that monetary policy shocks themselves do not affect other macroeconomic variables until the following quarter. ${ }^{17}$

\footnotetext{
${ }^{16}$ Because the federal funds rate is not seasonally adjusted, the reaction function was estimated with quarterly dummies to capture seasonality.

${ }^{17}$ Christiano, Eichenbaum, and Evans (1994) prefer this identification assumption to the alternative that monetary policy does not respond contemporaneously to macroeconomic variables but does have contemporaneous effects
} 


\subsubsection{Evaluating the choice of monetary policy reaction function}

After modeling the market for bank reserves and the Fed's response to reserve shocks, and after estimating structural VAR models over 1959-93 and several subperiods, Brunner (1994, p. 20) concluded that "the best way to uncover monetary policy shocks is to regress the federal funds rate on lags of appropriate variables that are in the Fed's information set." I follow his recommendation here.

Bernanke and Mihov (1995) nest a monetary policy reaction function like (4) in a structural VAR model with other policy variables (total and nonborrowed reserves and the discount rate) and test the restrictions implied by (4). They estimate their model over subperiods which are similar but not identical to the subperiods I use. They do not reject the restrictions implied by (4) in any subperiod, although they do not estimate their model over the 1979-82 subperiod and other results in their paper suggest the restrictions would be rejected for that subperiod. ${ }^{18}$ Brunner (1994) shows that, while monetary policy shocks do contribute to the variance of nonborrowed reserves in the 1979-82 subperiod but not at other times, federal funds rate shocks continue to be driven almost entirely by policy shocks in the 1979-82 subperiod, as in all the other subperiods he looks at. In short, the federal funds rate appears to be a good indicator of monetary policy in the 1979-82 subperiod and the best indicator over the remainder of my sample.

\subsection{Data construction}

The following data series were taken from the Federal Reserve Board's FAME database:

\begin{tabular}{|l|l|}
\hline Federal funds rate & US`RIFSPFF_N \\
Real GDP, 1990 prices & IFS‘\$Q11199B_R \\
M1 & US`M1 \\
Bank loans, excluding interbank & US`BCABL_BA \\
Bank securities & US‘BCABI_BA \\
\hline
\end{tabular}

Monthly data on the seasonally adjusted CPI (all urban consumers, U.S. city average, all items, 1982-84=100) was downloaded from the Bureau of Labor Statistics home page on April 4, 1996. Except for the Federal funds rate, all data are seasonally adjusted. The quarterly observations

on them. They base their preference on the fact that the alternative identification assumption implies that the contemporaneous positive correlation that exists between real GDP and federal funds rate shocks reflects the effect of policy on GDP.

${ }^{18}$ Their test uses monthly data. 
on the CPI and Federal funds rate are taken from the last month of the quarter. GDP growth is computed as the log difference of real GDP, multiplied by four to make it an annual rate.

$z(t)$ is constructed from monthly data on bank loans and bank securities as loans divided by the sum of loans and securities. The raw series for $z(t)$ is shown in the top panel of Figure 3. I am interested in the movements in $z(t)$ at the business cycle frequency and not the trend, so $z(t)$ was detrended by regressing it on time and time ${ }^{2}$. The detrended series for $z(t)$ is shown in the bottom panel of Figure $3 .^{19}$ In the regressions that follow, each quarter's observation of $z(t)$ is the average of the three detrended monthly observations. All regressions are run over the period 1960:Q1 1995:Q4.

\subsection{Measuring the effect of monetary policy on the real economy}

To measure the effect of monetary policy on the economy, I specify a linear model of GDP growth:

$$
\Delta Y_{t}=\mu+\sum_{k=1}^{K} \beta_{k} \Delta Y_{t-k}+\sum_{m=1}^{M} \gamma_{m} \epsilon_{t-m}^{m p}+\nu_{t}
$$

where $\nu$ represents shocks to GDP that are orthogonal to $\epsilon^{m p}$. GDP growth responds to monetary policy shocks with a lag of between one and $M$ quarters. I will refer to (5) as the "baseline model." 20

\subsection{Testing the implications of the model of bank customer relationships}

To see if monetary policy shocks are transmitted to the real economy with more force when $z(t)$ is at the boundary of its band, I augment the baseline regression (5) by allowing differential effects of monetary policy shocks depending on where $z(t)$ is within its band and whether the shock is expansionary or contractionary. I estimate the following regression:

$$
\Delta Y_{t}=\mu+\sum_{k=1}^{K} \beta_{k} \Delta Y_{t-k}+\sum_{m=1}^{M}\left\{\gamma_{m} \epsilon_{t-m}^{m p}+\sum_{i=T, B} \gamma_{m i} \epsilon_{t-m}^{m p, i}\right\}+\nu_{t}
$$

\footnotetext{
${ }^{19}$ The detrended $z(t)$ series has been mean-adjusted so that raw and detrended $z(t)$ are equal in $1995 \mathrm{Q} 4$.

${ }^{20}$ Ammer and Brunner (1995) also estimate the baseline model, along with several permutations that allow for asymmetric effects of monetary policy shocks.
} 
Figure 3: Raw data on $z(t)$ and detrended $z(t)$
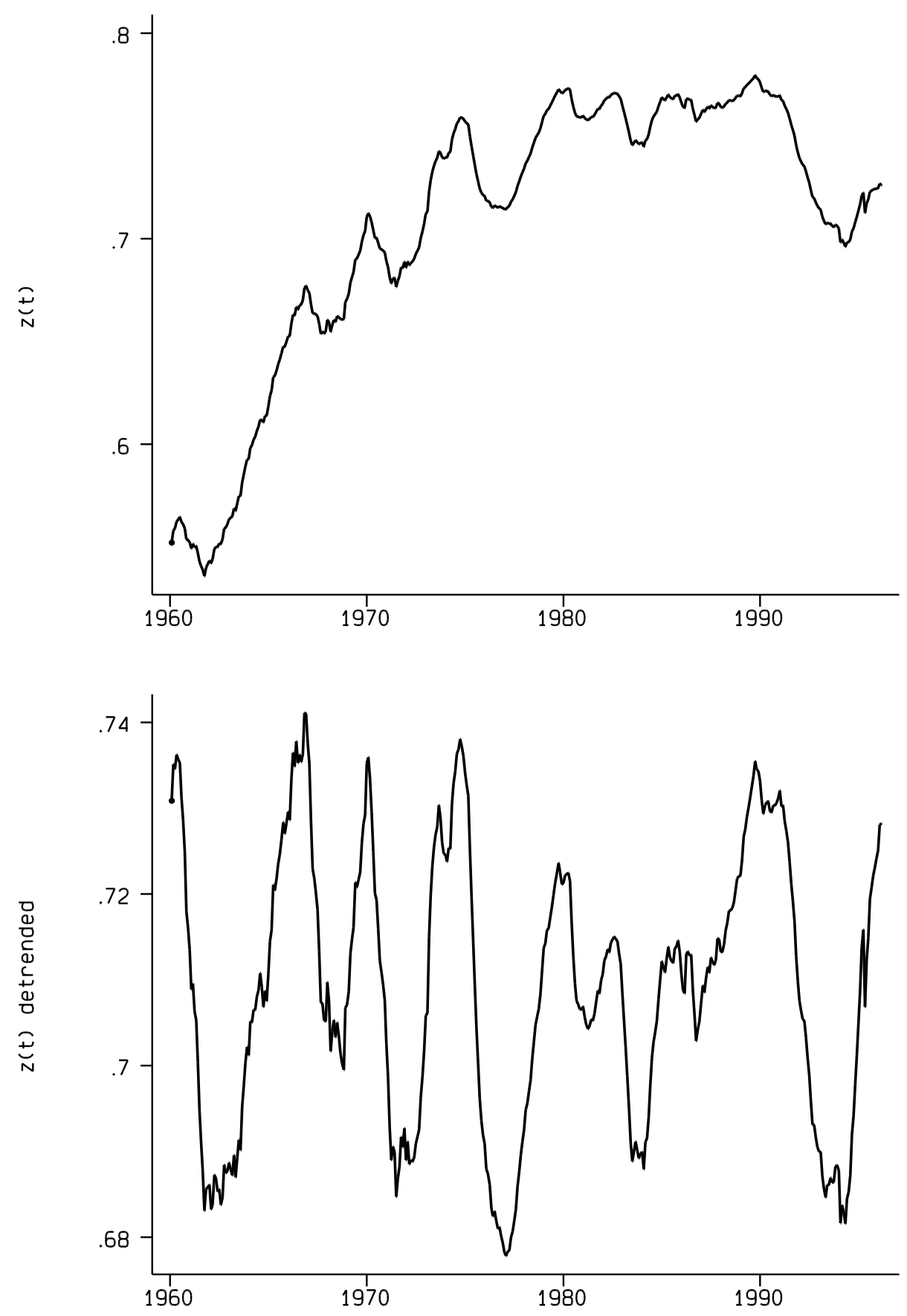
The differential effects of monetary policy will be measured through the regression coefficients on the following variables:

$$
\begin{aligned}
& \epsilon_{t}^{m p, T}= \begin{cases}\epsilon_{t}^{m p} & \text { if } z_{t} \geq u \text { and } \epsilon_{t}^{m p} \geq 0 \\
0 & \text { otherwise }\end{cases} \\
& \epsilon_{t}^{m p, B}= \begin{cases}\epsilon_{t}^{m p} & \text { if } z_{t} \leq \ell \text { and } \epsilon_{t}^{m p} \leq 0 \\
0 & \text { otherwise }\end{cases}
\end{aligned}
$$

I will test whether monetary policy transmission depends on the state of bank balance sheets by testing whether $\sum_{m=1}^{M} \gamma_{m T}$ and $\sum_{m=1}^{M} \gamma_{m B}$ equal zero. Since theory suggests that when $\sum_{m=1}^{M} \gamma_{m T}$ and $\sum_{m=1}^{M} \gamma_{m B}$ are non-zero, monetary transmission should be more powerful, I will test against a one-sided alternative hypothesis, that $\sum_{m=1}^{M} \gamma_{m T}$ and $\sum_{m=1}^{M} \gamma_{m B}$ are less than zero. Note that since we cannot observe when banks add and drop customers, $u$ and $\ell$ are parameters to be estimated, along with the $\beta$ 's, $\gamma$ 's, and $\mu$.

\subsection{Econometric complications}

As specified, the model has several features that make it difficult to obtain consistent and efficient estimates of the parameters of interest and to test the hypotheses outlined in the previous paragraph. One problem is that the lag lengths $K$ and $M$ are unknown. I use the Akaike information criterion computed on the joint model to choose all lag lengths. In general, the results change little when the Schwarz criterion is used to choose lag lengths. Results that would change if lag lengths had been chosen by the Schwarz criterion are noted in footnotes. ${ }^{21}$

\subsubsection{Two-stage estimation problem}

Estimating (5) or (6) requires putting $\epsilon^{m p}$ on the right-hand side of a regression. However, $\epsilon^{m p}$ is itself estimated as the residual from the monetary policy reaction function (4). While ordinary least squares could be used to sequentially estimate (4) followed by (5) or (6), the coefficient estimates would be less efficient than if (4) and (5) (or (6)) were estimated jointly.

To obtain asymptotically efficient coefficient estimates, I use the procedure described in Proposi-

\footnotetext{
${ }^{21}$ Tables showing the alternate results when lag lengths are chosen by the Schwarz criterion are available on request.
} 
tion 3.5 of Pagan (1986), which presents an asymptotically efficient estimator for a general two-stage estimation problem. I use Pagan's procedure to compute all the coefficient estimates in Tables 1-4. As implemented in my model, Pagan's procedure requires the following steps:

1. First-stage regression Estimate the monetary policy reaction function (4) with ordinary least squares (OLS).

2. Second-stage regression Estimate the effect of monetary policy on the real economy with (5) or (6) by OLS, using the OLS estimates of $\epsilon^{m p}$.

3. Double-length regression Construct a matrix $X$ consisting of the derivatives of the righthand side variables from the first and second stage regressions with respect to the parameters of the joint model (the $\alpha$ 's, $\beta$ 's, $\gamma^{\prime}$ s, and $\mu$ ). The matrix $X$ will be of dimension $2 T \times N P$, where $T$ is the sample size and $N P$ is the number of parameters in the joint model. Construct a matrix $Y$ consisting of the residuals of the first and second stage regression. The $Y$ matrix will be $2 T \times 1$. Divide each element of $X$ and $Y$ by the estimated standard error of the residual of that particular observation. Regress $Y$ on $X$.

4. Coefficient estimates The asymptotically efficient coefficient estimates are the sum of the sequential OLS coefficients and the double-length regression coefficients.

5. Standard errors Compute the variance-covariance matrix of the asymptotically efficient coefficient estimates as $\left(X^{\prime} X\right)^{-1}$.

Pagan's procedure produces coefficient estimates which are asymptotically equivalent to the maximum likelihood estimates of the joint model (4) and (5) (or (6)). Maximizing the likelihood

of the joint model directly, using a numerical maximization procedure on a computer, would be an alternative way to compute coefficient estimates and standard errors. I investigated this option but was unable to get the numerical maximization procedure to converge for many of the models in the paper.

\subsubsection{Estimating $u$ and $\ell$}

Estimating the threshold parameters $u$ and $\ell$ also introduces some complications. Conditional on $u$ and $\ell,(4)$ and (6) can be estimated jointly with the two-step procedure of Pagan (1986), but $u$ and $\ell$ cannot be estimated with standard techniques because the likelihood function is a step function 
with respect to $u$ and $\ell$. A small change in $u$ (from $u$ to $u+\Delta u$ ) will only change the likelihood when one or more observations exist with a value of $z$ between $u$ and $u+\Delta u$ (and similarly for $\ell$ ).

I estimate $u$ and $\ell$ by maximum likelihood, doing a grid search over possible values of $u$ and $\ell$, estimating (4) and (6) jointly with Pagan's procedure for each combination of $u$ and $\ell$, and taking as my estimate the combination of $u$ and $\ell$ that maximizes the joint likelihood of (4) and (6). ${ }^{22}$ Inference on $u$ and $\ell$ is also problematic. Standard results on the asymptotic normality of the maximum likelihood estimators of $u$ and $\ell$ assume a smooth objective function and thus do not apply here. ${ }^{23}$ Because the main hypotheses of interest for testing the model of bank behavior described in this paper relate to the $\gamma_{m T}$ and $\gamma_{m B}$ coefficients, and because I know of no way to construct an accurate confidence interval on the nuisance parameters $u$ and $\ell$, I simply present the consistent point estimates of $u$ and $\ell$ without providing $t$-statistics or confidence intervals. ${ }^{24}$

\subsubsection{Hypothesis testing with unidentified nuisance parameters}

Inference on the regression coefficients is also complicated by the need to estimate $u$ and $\ell$. When $u$ and $\ell$ are estimated from the data, a test excluding the terms with $\epsilon^{m p, T}$ (or $\epsilon^{m p, B}$ ) has a non-standard distribution, since $u$ (or $\ell$ ) is unidentified under the null hypothesis. Hansen (1991, 1996a) describes a transformation of standard $t$-statistics whose asymptotic distribution, while non-standard, can be simulated. Following Hansen (1991, section 6), I compute the test statistics on $\sum_{m=1}^{M} \gamma_{m T}=0$ and $\sum_{m=1}^{M} \gamma_{m B}=0$ against the alternative hypotheses $\sum_{m=1}^{M} \gamma_{m T}<0$ and $\sum_{m=1}^{M} \gamma_{m B}<0$ as $\inf _{u, l} t(u, l)$, where $t(u, l)$ is the usual $t$-statistic computed conditional on $u$ and $\ell$. I simulated the asymptotic distribution of the test statistic following the procedure in Hansen (1996a, p. 419). ${ }^{25}$ Throughout the paper, when I test a hypothesis involving unidentified nuisance parameters using Hansen's procedure, the $t$-statistic shown will be the inf $t$ statistic and will be marked with an asterisk. The $p$-value of the test, based on comparing the test statistic with its simulated asymptotic distribution, will also be provided.

\footnotetext{
${ }^{22}$ The grid for $u$ covered the top quartile of the distribution of $z(t)$, and the grid for $\ell$ covered the bottom quartile, with the restriction that $\epsilon^{m p, T}$ and $\epsilon^{m p, B}$ be non-zero in at least eight quarters. The restriction avoids the econometric problems associated with threshold models where the threshold is close to the boundary of the parameter space. See Andrews (1993, p. 826) for a discussion of these problems.

${ }^{23}$ Alternative results on the asymptotic normality of maximum likelihood estimators, which do not require a smooth objective function, exist but are beyond the scope of this paper.

${ }^{24}$ Hansen (1996b) describes a procedure to estimate a confidence interval on a threshold parameter such as $u$ or $\ell$, but Hansen's procedure relies on the assumption that the threshold effect vanishes asymptotically. This assumption is violated in the model in this paper, so Hansen's procedure is not used.

${ }^{25}$ I used 1,000 replications to simulate the distribution of each test statistic and the same grid for $u$ and $\ell$ described in footnote 22 .
} 
The fact that $u$ and $\ell$ are estimated, not known, also has the potential to affect the standard errors of the other parameter estimates. However, Chan (1993) shows that the maximum likelihood estimates of threshold parameters in a threshold autoregression (such as (6)) are superconsistent and asymptotically independent of the autoregression coefficients, so the asymptotic distribution of the other parameters in the model is unaffected by the fact that the threshold parameters are estimated, not known. As a result, I use the "usual" asymptotic standard errors to generate the $t$-statistics on coefficients other than $\gamma_{m T}$ and $\gamma_{m B}$ in (6).

\subsection{Results}

The first column of Table 1 shows the estimated coefficients of (5), the "baseline model." The second column of the table shows the estimated coefficients of (6), in which the effects of monetary policy shocks are allowed to differ depending on where $z(t)$ is within its band and whether the shock is expansionary or contractionary. ${ }^{26}$ Allowing for asymmetric effects of monetary policy as suggested by the simple model of bank behavior outlined above has a large effect on the estimated effects of monetary policy shocks. When $z(t) \geq u$, GDP falls by 8.7 percent in response to an exogenous one percentage point increase in the federal funds rate; when $z<u$, GDP falls by only 2.4 percent. Under the identifying assumption that there is no other source of asymmetry in monetary policy effects - an overly-strong assumption that will be relaxed below - the difference of 6.3 percentage points can be interpreted as the additional effect of the bank lending channel of monetary policy. When $z(t) \leq \ell$, GDP increases by 4.6 percent in response to an exogenous one percentage point drop in the federal funds rate; when $z>\ell$, GDP increases by only 2.4 percent. Under the same identifying assumption, the difference can be interpreted as a measure of the strength of the bank lending channel for expansionary monetary policy shocks. Both effects are as predicted by the model, and both show a substantial nonlinearity in monetary policy transmission. Only the former difference is statistically significant at the $5 \%$ level.

Although the estimates presented in Table 1 generally support a bank lending channel for monetary policy transmission, alternative interpretations exist. Before going on to test the bank lending channel against alternative interpretations, I will first address the problem of the lower bound $\ell$.

\footnotetext{
${ }^{26}$ The coefficients of the monetary policy reaction function are not reported.
} 
Table 1:

\begin{tabular}{|c|c|c|c|}
\hline & Baseline & $\begin{array}{l}\text { Allowing for effects } \\
\text { of bank behavior }\end{array}$ & $\begin{array}{c}\text { Allowing for effects } \\
\text { of bank behavior only } \\
\text { for contractionary shocks } \\
\text { ("reference model") }\end{array}$ \\
\hline$\mu$ & $\begin{array}{c}2.5 \\
(6.0)\end{array}$ & $\begin{array}{c}3.0 \\
(6.4)\end{array}$ & $\begin{array}{l}3.1 \\
(7.1)\end{array}$ \\
\hline$\sum_{k=1}^{K} \beta_{k}$ & $\begin{array}{l}.19 \\
(2.2)\end{array}$ & $\begin{array}{c}.13 \\
(1.4)\end{array}$ & $\begin{array}{c}.13 \\
(1.5)\end{array}$ \\
\hline$\sum_{m=1}^{M} \gamma_{m}$ & $\begin{array}{l}-2.4 \\
(-2.7)\end{array}$ & $\begin{array}{l}-2.4 \\
(-2.1)\end{array}$ & $\begin{array}{l}-1.9 \\
(-2.1)\end{array}$ \\
\hline$\sum_{m=1}^{M} \gamma_{m T}$ & & $\begin{array}{l}-6.3 \\
(-2.8)^{*} \\
p<.01\end{array}$ & $\begin{array}{c}-7.2 \\
(-3.3)^{*} \\
p<.01\end{array}$ \\
\hline$\sum_{m=1}^{M} \gamma_{m B}$ & & $\begin{array}{l}-2.2 \\
(-1.3)^{*} \\
p=.14\end{array}$ & \\
\hline$u$ & & .7223 & .7223 \\
\hline$\ell$ & & .6873 & \\
\hline $\mathrm{K}, \mathrm{M}$ & 1,3 & 1,4 & 1,3 \\
\hline$-\mathrm{LL}$ & 499.6 & 488.1 & 493.0 \\
\hline $\mathrm{AIC}$ & 1099.3 & 1098.2 & 1094.0 \\
\hline $\mathrm{SC}$ & 1247.8 & 1279.4 & 1254.3 \\
\hline
\end{tabular}

Note: Asymptotic $t$-statistics are in parentheses. The $t$-statistics marked with an asterisk have non-standard distributions because of the presence of unidentified nuisance parameters. $p$-values are provided for these tests. These $t$-statistics and $p$-values are computed as described in the text.

$\mathrm{LL}=\log$ likelihood

$\mathrm{AIC}=$ Akaike information criterion $=-2 \times \log$ likelihood $+2 \times$ number of parameters

$\mathrm{SC}=$ Schwarz criterion $=-2 \times \log$ likelihood + number of parameters $\times \ln ($ sample size $)$ 


\subsection{Re-estimating the model without the lower bound $\ell$}

The second column of Table 1 shows that while the point estimate of the effect of a monetary policy shock is larger for expansionary shocks when $z \leq \ell$, the hypothesis that this effect is equal to the effect when $z(t)$ is in the middle of its band $\left(\sum_{m=1}^{M} \gamma_{m B}=0\right)$ cannot be rejected. This result suggests omitting the differential effect at the lower bound $\ell$ from the estimated model. By omitting $\ell$ from the model, I omit the magnification that the bank lending channel provides for expansionary monetary policy shocks when $z(t)$ is at the bottom of its band. This omission is actually quite common in the monetary policy transmission literature. ${ }^{27}$ In addition, it may be justified by considering the link between bank lending and real economic activity, which I have only briefly touched upon so far.

It is reasonable to think that the link between bank lending and economic activity will be stronger and more immediate for contractionary monetary policy shocks than for expansionary shocks. A contraction of bank lending cuts some firms off from credit, which may cause the firms to reduce their activity relatively quickly. An expansion of bank lending may take longer to show up in increased economic activity, if the new lending goes to finance new firms or expansion at existing firms, both of which may take some time before they result in increased production. The bank lending channel should still operate for expansionary shocks, but the effects may be less immediate and therefore harder to find in the data.

For these reasons, I re-estimated the model without the lower bound $\ell$. Results are shown in the third column of Table 1 . Removing the lower bound $\ell$ is equivalent to forcing expansionary shocks that occur when $z(t) \leq \ell$ to have the same effect as shocks when $z(t)$ is in the interior of its band. The change has little effect on the estimated coefficients. The prediction of the model - that contractionary shocks have a larger effect on GDP when $z(t) \geq u$-is still supported. I will take this as the "reference model"; in the next section I will compare it to alternative models of asymmetric monetary policy effects. ${ }^{28}$

\footnotetext{
${ }^{27}$ For example, Romer and Romer (1990) study only contractionary monetary policy shocks.

${ }^{28}$ If the lag lengths in Table 1 were instead chosen with the Schwarz criterion, the conclusions drawn in the text regarding the statistical significance of the bank lending channel would be unaffected. The main difference would be that, with the shorter lag lengths chosen by the Schwarz criterion, $\sum_{m=1}^{M} \gamma_{m}$ is statistically insignificantly different from zero in the last two columns and the magnitudes of $\sum_{m=1}^{M} \gamma_{m T}$ and $\sum_{m=1}^{M} \gamma_{m B}$ are smaller.
} 


\subsection{Testing the model against some alternatives}

Although the results discussed above are consistent with a bank lending channel of monetary transmission, they do not prove that such a channel is important. If there are other transmission mechanisms whose strength varies over time in a way that is correlated with the strength of the bank lending channel, the nonlinear effects of monetary policy shocks uncovered in Table 1 are a convolution of the bank lending channel and those other transmission channels. I will assume that the strength of the user cost of capital channel does not vary with the business cycle, so I look to other transmission channels for an alternative interpretations of the above results. In effect, I conduct a "horse race" between monetary policy transmission channels.

I consider two types of alternative transmission channels: a "broad credit channel," and the set of transmission channels that imply an asymmetric effect of contractionary and expansionary monetary policy shocks. A broad credit channel implies, as discussed in section 2.1 above and as tested by Ammer and Brunner (1995), that monetary policy should be more effective when the economy is in a recession. The set of transmission channels that imply a stronger effect of contractionary shocks include channels based on real effects, such as transmission through irreversibilities in investment, as well as the purely nominal channel of wage/price stickiness discussed in Cover (1992) and Ammer and Brunner (1995). Irreversibilities in investment imply a stronger effect for contractionary shocks because contractionary shocks tend to increase uncertainty about the future state of the economy. ${ }^{29}$ For brevity, I will refer to these channels as "asymmetric channels" in what follows. Because the bank lending channel also relies on the asymmetry between contractionary and expansionary shocks, it is important to distinguish, if possible, between the more general set of channels that imply a stronger effect of contractionary monetary policy shocks, and the bank lending channel, which implies a stronger effect only when $z(t) \geq u$.

I make the following identifying assumptions:

1. Transmission of monetary policy shocks through the user cost of capital channel is constant over the business cycle.

2. Transmission of monetary policy shocks through the bank lending channel implies a stronger effect when $z(t) \geq u$ and the shock is contractionary.

3. Transmission of monetary policy shocks through a broad credit channel implies a stronger

\footnotetext{
${ }^{29}$ See Leahy and Whited (1995) for evidence on the link between uncertainty and irreversible investment.
} 
effect during a recession.

4. Transmission of monetary policy shocks through the "asymmetric channels" implies a stronger effect when the shock is contractionary.

Using these assumptions, I can identify time periods when one, two, three, or all four transmission channels are operating. By estimating the differences in the strength of monetary policy transmission at different points in time, I can measure the differences in strength of the various channels.

To do this, I augment the baseline model (5) with dummy variables interacted with the monetary policy shock to allow for the three channels described above. The bank lending channel will operate only when $z \geq u$ and the monetary policy shock is contractionary. Let $D_{t}^{1}=1$ in all quarters when both conditions hold. The broad credit channel implies a stronger effect of shocks during a recession. Let $D_{t}^{2}=1$ if the quarter falls within an NBER recession. ${ }^{30}$ The asymmetric channels imply a stronger effect of contractionary monetary policy shocks. Let $D_{t}^{3}=1$ if the monetary policy shock is contractionary. I run the following regression:

$$
\Delta Y_{t}=\mu+\sum_{k=1}^{K} \beta_{k} \Delta Y_{t-k}+\sum_{m=1}^{M}\left\{\gamma_{m} \epsilon_{t-m}^{m p}+\sum_{i=1}^{3} \gamma_{m}^{i} D_{t-m}^{i} \epsilon_{t-m}^{m p}\right\}+\nu_{t}
$$

and perform the following hypothesis tests, testing for no transmission through each individual channel:

\begin{tabular}{|l|l|}
\hline Bank lending channel & $H_{1}: \sum_{m=1}^{M} \gamma_{m}^{1}=0$ \\
Broad credit channel & $H_{2}: \sum_{m=1}^{M} \gamma_{m}^{2}=0$ \\
Asymmetric channels & $H_{3}: \sum_{m=1}^{M} \gamma_{m}^{3}=0$ \\
\hline
\end{tabular}

For each test, the theory suggests a one-sided alternative:

\begin{tabular}{|l|l|}
\hline Bank lending channel & $H_{1}^{\prime}: \sum_{m=1}^{M} \gamma_{m}^{1}<0$ \\
Broad credit channel & $H_{2}^{\prime}: \sum_{m=1}^{M} \gamma_{m}^{2}<0$ \\
Asymmetric channels & $H_{3}^{\prime}: \sum_{m=1}^{M} \gamma_{m}^{3}<0$ \\
\hline
\end{tabular}

I will be particularly interested in the test of $H_{1}$. The test of $H_{1}$ is less likely to suffer from omitted variable bias than the earlier test of the bank lending channel in Table 1, since two external sources of variation in the strength of monetary policy transmission are controlled for.

\footnotetext{
${ }^{30} \mathrm{~A}$ recessionary quarter is defined here as a quarter where two or three months come after a peak month up to and including a trough month, as dated by the NBER.
} 
Figure 4 examines whether multicollinearity will present an obstacle to my tests. The figure shows how often multiple transmission channels are working at the same time. ${ }^{31}$ The three circles represent the events $z \geq u, \epsilon^{m p} \geq 0$, and a recession. The number of quarters in which each event is true is shown on the figure. The bank lending channel operates in the 21 quarters when both $z \geq u$ and $\epsilon^{m p} \geq 0$, enclosed by a green line. The broad credit channel operates in the 24 quarters when a recession is occurring, enclosed by a blue line. The asymmetric channels operate in the 78 quarters when $\epsilon^{m p} \geq 0$, enclosed by a red line. The bank lending channel and the broad credit channel operate simultaneously in 7 quarters, with only the former operating in an additional 14 quarters and only the latter in an additional 17 quarters. Although by definition the asymmetric channels must be operating in all 21 quarters that the bank lending channel is operating, the asymmetric channels are also operating in an additional 52 quarters. In short, there appears to be enough variation in the data to separately identify the three channels, if any effects exist to be identified.

I estimate the horse race regression (7) jointly with the monetary policy reaction function (4) using the technique described in section 5.5. Results for the tests of $H_{1}, H_{2}$, and $H_{3}$ are shown in Table 2. Since the null hypotheses of no effect have one-sided alternatives, critical values for a one-tailed test will be used to evaluate the three hypotheses. For each hypothesis, the sum of coefficients that is hypothesized to equal zero is shown, along with its $t$-statistic. Again the test of the bank lending channel has a non-standard distribution because the parameter $u$ is unidentified under $H_{1}$.

According to the evidence in Table 2, the hypothesis of no bank lending channel, $H_{1}$, can be rejected. The hypothesis of no broad credit channel, $H_{2}$, and the hypothesis of no asymmetric channels, $H_{3}$, cannot be rejected. While the coefficients on all three channels are negative, as expected, the bank lending channel has the largest coefficients and the only effect that is statistically significantly different from zero. The estimated effect of the bank lending channel in Table 2 is smaller than the estimated effect in the rightmost column of Table 1, suggesting that an omitted variable bias could have been inflating the effect found in Table $1 .{ }^{32}$

\footnotetext{
${ }^{31}$ The estimates of $u$ and $\epsilon^{m p}$ used to construct the figure are taken from the "reference model" in Table 1.

${ }^{32}$ In a previous version of the paper, I presented an additional table showing results when I substituted "high leverage in the nonfinancial sector" for "recession" as the way to identify quarters when broad credit channel effects would likely be strongest. These results did not support the broad credit channel hypothesis, either.
} 
Figure 4: Which transmission channels operate when?

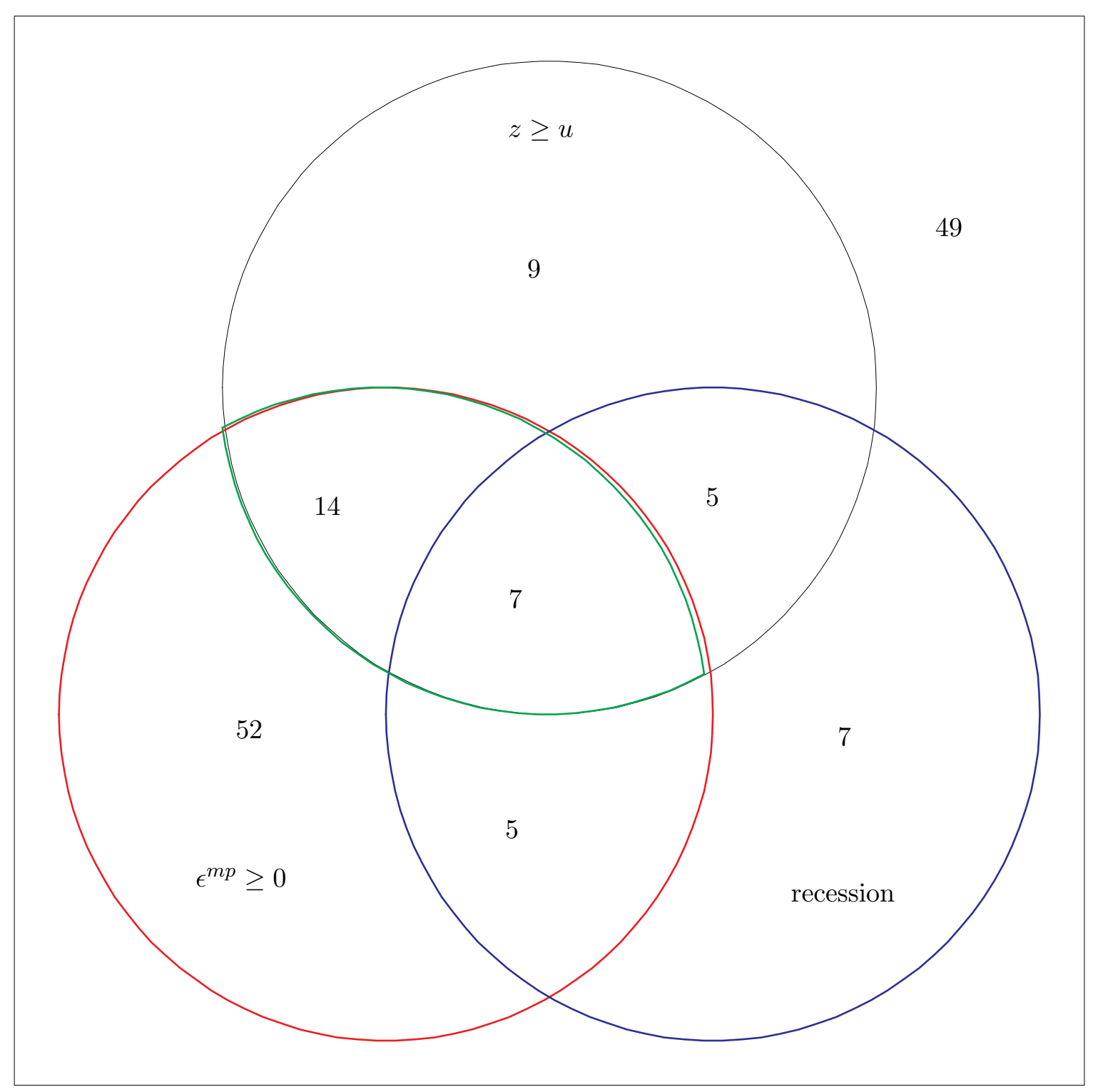

The three circles represent the events $z \geq u, \epsilon^{m p} \geq 0$, and a recession. The number of quarters in which each event is true are shown on the figure. The bank lending channel operates in the 21 quarters when both $z \geq u$ and $\epsilon^{m p} \geq 0$, enclosed by a green line. The broad credit channel operates in the 24 quarters when a recession is occurring, enclosed by a blue line. The asymmetric channels operate in the 78 quarters when $\epsilon^{m p} \geq 0$, enclosed by a red line. Data cover 1959Q1 - 1995Q4. The estimates of $u$ and $\epsilon^{m p}$ are taken from the "reference model" in Table 1. 
Table 2: Comparing the three transmission channels

\begin{tabular}{|c|c|}
\hline $\begin{array}{l}\text { bank lending channel } \\
H_{1}: \quad \sum_{m=1}^{4} \gamma_{m}^{1}=0\end{array}$ & $\begin{array}{c}-5.3 \\
(-2.1)^{*} \\
p<.01\end{array}$ \\
\hline $\begin{array}{l}\text { broad credit channel } \\
H_{2}: \quad \sum_{m=1}^{4} \gamma_{m}^{2}=0\end{array}$ & $\begin{array}{c}-3.6 \\
(-1.1)\end{array}$ \\
\hline $\begin{array}{l}\text { asymmetric channels } \\
H_{3}: \quad \sum_{m=1}^{4} \gamma_{m}^{3}=0\end{array}$ & $\begin{array}{l}-0.8 \\
(-0.3)\end{array}$ \\
\hline $\begin{array}{l}\text { Lag lengths } \\
\text {-LL } \\
\text { AIC } \\
\text { SC }\end{array}$ & $\begin{array}{c}1,4 \\
484.0 \\
1096.1 \\
1286.1\end{array}$ \\
\hline
\end{tabular}

Note: Asymptotic $t$-statistics are in parentheses. For the one-sided hypothesis tests described in the text, the appropriate $5 \%$ critical value is -1.645 . The $t$-statistic marked with an asterisk has a non-standard distribution because of the presence of an unidentified nuisance parameter. The $p$-value is provided for this test. The $t$-statistic and $p$-value are computed as described in the text.

\subsection{Has the strength of the bank lending channel changed over time?}

In the preceding section, I documented the strength of the bank lending channel of monetary policy transmission. Given the vast changes in the financial structure of the U.S. economy over the 35 years covered in this study, one can ask whether the strength of the bank lending channel, or any of the other channels tested above, has varied over time.

To look for changes over time, I begin with the "horse race" model from the preceding section, split the sample in half, and allow the regression coefficients and threshold parameters in each half of the sample to differ. ${ }^{33}$ Results are shown in Table 3.

Table 3 suggests the strength of the bank lending channel has declined over time. The $\gamma^{1}$ coefficients decline in magnitude and in statistical significance from the first half of the sample to the second. The direction of the change accords with one's prior belief that bank lending has become relatively less important to the economy over time. However, the results in Table 3 should be treated with some skepticism since an already small sample of 148 quarters is being divided in

\footnotetext{
${ }^{33}$ For the split sample regression, the grid of possible values of $u$ included the upper quartile of $z(t)$, with the restriction that the bank lending channel operate in at least four quarters in each half of the sample period.
} 
Table 3: Looking for a structural break

\begin{tabular}{|l|c|c|}
\cline { 2 - 3 } \multicolumn{1}{l|}{} & $\begin{array}{c}1960- \\
1977\end{array}$ & $\begin{array}{c}1978- \\
1995\end{array}$ \\
\hline bank lending channel & -7.0 & -4.5 \\
$H_{1}: \quad \sum_{m=1}^{4} \gamma_{m}^{1}=0$ & $(-3.9)^{*}$ & $(-0.8)^{*}$ \\
& $p<.01$ & $p=.42$ \\
& & \\
\hline broad credit channel & & \\
$H_{2}: \quad \sum_{m=1}^{4} \gamma_{m}^{2}=0$ & -2.6 & 3.7 \\
& $(-0.6)$ & $(0.5)$ \\
& & \\
\hline asymmetric channels & & .44 \\
$H_{3}: \quad \sum_{m=1}^{4} \gamma_{m}^{3}=0$ & .02 & $(0.1)$ \\
& $(0.0)$ & \\
\hline Lag lengths & \multicolumn{2}{|c|}{1,4} \\
-LL & \multicolumn{2}{|c|}{110.2} \\
AIC & \multicolumn{2}{|c|}{1432.9} \\
SC & \multicolumn{2}{|c|}{} \\
\hline
\end{tabular}

Note: Asymptotic $t$-statistics are in parentheses. For the one-sided hypothesis tests described in the text, the appropriate $5 \%$ critical value is -1.645 . The $t$-statistics marked with an asterisk have non-standard distributions because of the presence of unidentified nuisance parameters. $p$-values are provided for these tests. These $t$-statistics and $p$-values are computed as described in the text. 
half. For example, the bank lending channel is estimated to operate in nine quarters in the first half of the sample but only four quarters in the second half.

\section{Two robustness checks}

The results presented above support the existence of a bank lending channel of monetary policy transmission that leads to a nonlinear effect of monetary policy on the real economy. However, alternative stories exist to explain the nonlinear effect. Two such stories are examined in this section. The first story suggests that the monetary policy reaction function is misspecified in a way that spuriously increases the negative correlation between the monetary policy shock and GDP at cyclical peaks. The second suggests that bank balance sheets have explanatory power for monetary policy transmission simply because they are correlated with the level of inventories. In this section, I investigate each of these stories in turn.

\subsection{Is the monetary policy reaction function misspecified?}

The monetary policy reaction function (4) allows the federal funds rate to respond endogenously to current and past real GDP growth, current and past CPI inflation, past M1, and past values of the federal funds rate. One potential misspecification is an insufficient recognition of the role played by cyclical factors in the monetary policy reaction function. If the Fed regularly reacted at the peak of the business cycle to tighten monetary policy and if the right-hand side variables in the monetary policy reaction function did not adequately capture this regularity, the monetary policy shock $\epsilon^{m p}$ would be too high at the peak of the cycle. Since a downturn in GDP growth by definition follows a cyclical peak, the negative correlation between GDP growth and the monetary policy shock would be exaggerated by such a misspecification.

Such a misspecification would contaminate my "reference model," which allows the strength of the negative correlation between GDP growth and monetary policy shocks to vary in a way that is correlated with bank balance sheets. Since in practice $z(t)$ tends to peak near business cycle peaks, such a misspecification of the monetary policy reaction function would have the potential to contaminate the tests of the bank lending channel described above.

To investigate whether such a contamination is driving the results presented above, I reestimated the monetary policy reaction function, replacing the current and lagged real GDP growth terms with the current and lagged GDP gap. The GDP gap is measured as the deviation of real 
GDP from a piecewise exponential trend with a kink in the fourth quarter of $1973 .{ }^{34}$ I re-estimated the "reference model" from Table 1 with the modified reaction function.

The results of the robustness check are shown in the first column of Table 4 . While the differential effect of monetary policy contractions on real GDP when $z \geq u$ declines with the change in the reaction function, from an additional 7.2 percent decline in real GDP to an additional 2.8 percent decline, the effect is still statistically significant $(p$-value $=.05)$. I conclude that misspecification of the monetary policy reaction function cannot explain the above results.

\subsection{Is correlation with inventory demand driving the results?}

A second potential explanation emphasizes the importance of inventory investment for business cycle fluctuations. According to this explanation, when inventories are unusually high, a monetary policy contraction is more likely to lead to a recession. This story suggests that bank balance sheets have explanatory power in the results presented above only because they are correlated with the level of inventories in the economy. In effect, rather than identifying an effect of bank loan supply on the real economy, the regressions estimated above have identified an effect of inventory demand.

If inventories and bank balance sheets were perfectly correlated, there would be no way with the data used in this paper to differentiate between the inventory-based explanation and my bank balance sheet-based explanation. Figure 5 shows that the correlation is less than perfect. Although there are times when inventories and $z(t)$ are high at the same time, there are also times when they do not move together. Based on the figure, I attempt to differentiate between the two stories.

To differentiate between the two stories, I modify the reference model to allow another nonlinearity to affect the relationship between monetary policy contractions and GDP growth. The additional nonlinear effect will occur when inventories are "high." I augment the reference model with an additional term to reflect an interaction with inventories. The augmented model is:

$$
\Delta Y_{t}=\mu+\sum_{k=1}^{K} \beta_{k} \Delta Y_{t-k}+\sum_{m=1}^{M}\left\{\gamma_{m} \epsilon_{t-m}^{m p}+\sum_{i=T, I N V} \gamma_{m i} \epsilon_{t-m}^{m p, i}\right\}+\nu_{t}
$$

\footnotetext{
${ }^{34}$ In other words, the GDP gap is the residual from a regression of log real GDP on $\{1,2, \ldots, 67,68,68, \ldots, 68\}$ and $\{0, \ldots, 0,1,2, \ldots, 88\}$.
} 
Table 4: Two robustness checks

\begin{tabular}{|c|c|c|}
\hline & $\begin{array}{l}\text { Reaction function } \\
\text { includes GDP gap } \\
\text { on right-hand side }\end{array}$ & $\begin{array}{c}\text { Allow an additional } \\
\text { effect of inventory- } \\
\text { sales ratio }\end{array}$ \\
\hline$\mu$ & $\begin{array}{c}2.2 \\
(5.3)\end{array}$ & $\begin{array}{c}2.3 \\
(5.8)\end{array}$ \\
\hline$\sum_{k=1}^{K} \beta_{k}$ & $\begin{array}{c}.33 \\
(3.3)\end{array}$ & $\begin{array}{c}.26 \\
(3.1)\end{array}$ \\
\hline$\sum_{m=1}^{M} \gamma_{m}$ & $\begin{array}{l}0.17 \\
(.33)\end{array}$ & $\begin{array}{l}0.03 \\
(.06)\end{array}$ \\
\hline$\sum_{m=1}^{M} \gamma_{m T}$ & $\begin{array}{c}-2.8 \\
(-1.8)^{*} \\
p=.05\end{array}$ & $\begin{array}{c}-2.2 \\
(-2.4)^{*} \\
p=.04\end{array}$ \\
\hline$\sum_{m=1}^{M} \gamma_{m I N V}$ & & $\begin{array}{c}-.94 \\
(-.46)^{*} \\
p=.62\end{array}$ \\
\hline$u$ & .7223 & .7252 \\
\hline$i \hat{n} v$ & & 2.47 \\
\hline $\mathrm{K}, \mathrm{M}$ & 2,1 & 1,1 \\
\hline$-\mathrm{LL}$ & 487.1 & 489.0 \\
\hline AIC & 1076.3 & 1082.0 \\
\hline $\mathrm{SC}$ & 1227.7 & 1235.8 \\
\hline
\end{tabular}

Note: Asymptotic $t$-statistics are in parentheses. The $t$-statistics marked with an asterisk have non-standard distributions because of the presence of unidentified nuisance parameters. $p$-values are provided for these tests. These $t$-statistics and $p$-values are computed as described in the text.

$\mathrm{LL}=\log$ likelihood

AIC $=$ Akaike information criterion $=-2 \times \log$ likelihood $+2 \times$ number of parameters

$\mathrm{SC}=$ Schwarz criterion $=-2 \times \log$ likelihood + number of parameters $\times \ln ($ sample size $)$ 
Figure 5: $z(t)$ and the inventory-sales ratio

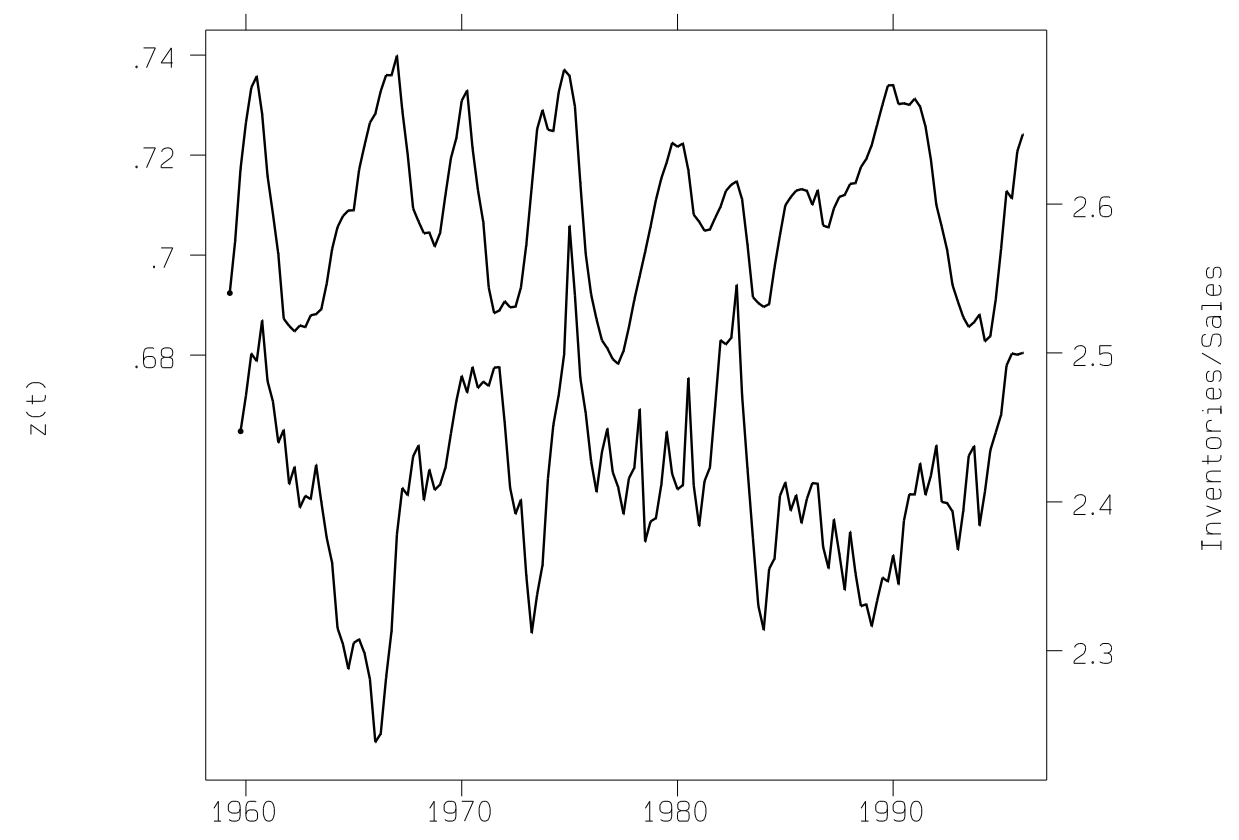

where $\epsilon_{t}^{m p, T}$ is defined as before and

$$
\epsilon_{t}^{m p, I N V}= \begin{cases}\epsilon_{t}^{m p} & \text { if } i n v_{t} \geq \hat{i n} v \text { and } \epsilon_{t}^{m p} \geq 0 \\ 0 & \text { otherwise }\end{cases}
$$

where $i \hat{n} v$ is a threshold parameter to be estimated from the data in the same way as $u$. The coefficients $\gamma_{m I N V}$ will capture any nonlinear effect related to a high level of inventories in the same way that the $\gamma_{m T}$ coefficients have captured a nonlinear effect related to bank balance sheets. I will measure inventories as the detrended ratio of inventories to final sales (in constant dollars). ${ }^{35}$

Results of estimating (8) are shown in the second column of Table 4. Comparing with the reference model from Table 1, the coefficients on $\gamma_{m T}$ are smaller, but the hypothesis of no bank lending channel is still rejected at the 5 percent level. The term added to capture any nonlinearity based on the inventory-sales ratio is negative but is not statistically significantly different from zero. In sum, when the data are allowed to choose whether inventories or bank balance sheets do a

\footnotetext{
${ }^{35}$ The inventory-sales ratio is detrended by regressing on time and time ${ }^{2}$ and has been mean-adjusted so the unadjusted and detrended ratios are equal in 1995:Q4. Figure 5 shows the detrended ratio. The source for the inventory-sales data is the Survey of Current Business, Table 5.13.
} 
better job of identifying the nonlinear effect of monetary policy on the real economy, bank balance sheets are the preferred choice.

\section{Conclusions}

Economists have struggled to identify the channels of monetary policy transmission. Identifying monetary transmission through bank lending has proven to be especially challenging, because of the difficulty in separately identifying changes in the supply of and demand for bank loans. The innovation in this paper is to identify the bank lending channel of monetary policy by applying insights from a simple model of bank behavior incorporating long-term customer relationships. The model suggests that the strength of the bank lending channel should depend on the condition of bank balance sheets in a nonlinear fashion.

To test for a bank lending channel, I combine data on bank balance sheets with a standard linear autoregressive model of real GDP growth. Monetary policy shocks do have a stronger effect on real GDP growth during periods when the bank lending channel should be operating. This evidence is consistent with an important role for bank lending in transmitting monetary policy to the real economy. A second, stronger test of the bank lending channel puts it in a "horse race" with two other alternative monetary transmission channels. The bank lending channel is the strongest of the three. Investigating two alternative explanations for the results showed no reason to prefer them to the bank lending channel explanation.

The association between bank balance sheets and the strength of monetary policy transmission documented in this paper appears robust. I explain the association as the consequence of a "bank lending channel" of monetary policy transmission. One feature of my methodology is that, by looking directly at the link between monetary policy and real GDP, I never observe whether bank loan supply actually does fall following a monetary policy contraction. However, a recent paper by Kashyap and Stein (1996) using bank-level micro data does look at that intermediate step and finds that the response of bank lending to monetary policy does depend on a bank's balance sheet. In summary, it is hard to think of a reason other than a bank lending channel of monetary policy transmission that could account for this body of evidence.

Several topics remain for future research into the bank lending channel before the conclusions of this paper can be confidently applied to policymaking. More work should be done to make sure one can identify periods when $z(t)$ is at one of its boundaries. One possible extension would be to allow 
the boundaries $u$ and $\ell$ to vary over time. Also, one would like to be able to more precisely identify how the bank lending channel affects the real economy. One extension could be to test for bank lending channel effects separately for small firms and large firms. Applying the model to state-level data could reveal something about the role the bank lending channel plays in regional business cycles. Finally, one might be able to learn something about the relationship between the structure of a nation's financial system and the channels of monetary policy transmission by estimating the models in this paper with data from other countries at different stages of financial development. 


\section{References}

Ammer, John and Allen Brunner, 1995. When is monetary policy effective? International Finance Discussion Paper No. 520. Washington, DC: Board of Governors of the Federal Reserve System (September).

Andrews, D. W. K., 1993. Tests for parameter instability and structural change with unknown change point. Econometrica 61, 821-856.

Bentolila, Samuel and Giuseppe Bertola, 1990. Firing costs and labour demand: How bad is Eurosclerosis? Review of Economic Studies 57, 381-402.

Berger, Allen N. and Gregory F. Udell, 1995. Relationship lending and lines of credit in small firm finance. Journal of Business 68:3, 351-382 (July).

Bernanke, Ben S. and Alan S. Blinder, 1992. The federal funds rate and the channels of monetary policy transmission. American Economic Review 82:4, 901-21 (September).

Bernanke, Ben and Mark Gertler, 1995. Inside the black box: the credit channel of monetary policy transmission. Journal of Economic Perspectives 9:4, 27-48 (Fall).

Bernanke, Ben and Ilian Mihov, 1995. Measuring monetary policy. Working paper No. 5145. Cambridge, MA: National Bureau of Economic Research (June).

Bertola, Giuseppe, 1988. Adjustment Costs and Dynamic Factor Demands: Investment and Employment under Uncertainty. Ph.D. Thesis, MIT.

Brunner, Allen, 1994. The federal funds rate and the implementation of monetary policy: Estimating the Federal Reserve's reaction function. International Finance Discussion Paper No. 466. Washington, DC: Board of Governors of the Federal Reserve System (May).

Chan, K.S., 1993. Consistency and limiting distribution of the least squares estimator of a threshold autoregressive model. The Annals of Statistics 21, 520-533.

Christiano, Lawrence, Martin Eichenbaum and Charles Evans, 1994. Identification and the effects of monetary policy shocks. Working paper WP-94-7. Chicago: Federal Reserve Bank of Chicago (May).

Constantinides, George M. and Scott F. Richard, 1978. Existence of optimal simple policies for discounted-cost inventory and cash management in continuous time. Operations Research 26:4, 620-636 (July-August).

Cover, James Peery, 1992. Asymmetric effects of positive and negative money-supply shocks. Quarterly Journal of Economics 107:4, 1261-1282 (November).

Dixit, Avinash, 1989. Entry and exit decisions under uncertainty. Journal of Political Economy 97, 620-638 (June).

Dumas, Bernard, 1989. Super contact and related optimality conditions. Technical Working Paper No. 77. Cambridge, MA: National Bureau of Economic Research (April). 
Eichenbaum, Martin, 1994. Comment. In Mankiw, N. Gregory, ed., Monetary policy. Chicago: University of Chicago Press.

Fazzari, Steven M., 1995. Discussion. In Joe Peek and Eric S. Rosengren (eds.), Is bank lending important for the transmission of monetary policy? Conference Series No. 39. Boston: Federal Reserve Bank of Boston.

Gertler, Mark and Simon Gilchrist, 1994. Monetary policy, business cycles and the behavior of small manufacturing firms. Quarterly Journal of Economics 109:2, 309-340 (May).

Gibson, Michael S., forthcoming. More evidence on the link between bank health and investment in Japan. Journal of the Japanese and International Economies.

Gilchrist, Simon G. and Egon Zakrajšek, 1995. The importance of credit for macroeconomic activity: identification through heterogeneity. In Joe Peek and Eric S. Rosengren (eds.), Is bank lending important for the transmission of monetary policy? Conference Series No. 39. Boston: Federal Reserve Bank of Boston.

Hansen, Bruce E., 1991. Inference when a nuisance parameter is not identified under the null hypothesis. Rochester Center for Economic Research Working Paper No. 296. Rochester, NY: The University of Rochester (September).

Hansen, Bruce E., 1996a. Inference when a nuisance parameter is not identified under the null hypothesis. Econometrica 64:2, 413-430 (March).

Hansen, Bruce E., 1996b. Inference in TAR models. Unpublished working paper. Chestnut Hill, MA: Boston College Department of Economics (December).

Harrison, J. Michael, 1985. Brownian Motion and Stochastic Flow Systems. John Wiley and Sons.

Kashyap, Anil K. and Jeremy C. Stein, 1994. Monetary policy and bank lending. In Mankiw, N. Gregory, ed., Monetary policy. Chicago: University of Chicago Press.

Kashyap, Anil K. and Jeremy C. Stein, 1995. The impact of monetary policy on bank balance sheets. Carnegie-Rochester Conference Series on Public Policy 42, 151-196 (June).

Kashyap, Anil K. and Jeremy C. Stein, 1996. What do a million banks have to say about the transmission of monetary policy? Working paper, University of Chicago Graduate School of Business and MIT Sloan School of Management (November).

Kashyap, Anil K., Jeremy C. Stein, and David W. Wilcox, 1993. Monetary policy and credit conditions: Evidence from the composition of external finance. American Economic Review 83:1, 78-98 (March).

Kashyap, Anil K., Jeremy C. Stein, and David W. Wilcox, 1996. Monetary policy and credit conditions: Evidence from the composition of external finance: reply. American Economic Review 86:1, 310-314 (March).

King, Stephen R., 1986. Monetary transmission: Through bank loans or bank liabilities? Journal of Money, Credit, and Banking 18, 290-303. 
Leahy, John V. and Toni M. Whited, 1995. The effect of uncertainty on investment: some stylized facts. Working Paper No. 4986. Cambridge, MA: National Bureau of Economic Research (January).

Lummer, S. L., and J. J. McConnell, 1989. Further evidence on the bank lending process and the capital market response to bank loan agreements. Journal of Financial Economics 25, $99-122$.

McCallum, John, 1991. Credit rationing and the monetary transmission mechanism. American Economic Review 81:4, 946-951 (September).

Miron, Jeffrey A., Christina D. Romer and David N. Weil, 1994. Historical perspectives on the monetary transmission mechanism. In Mankiw, N. Gregory, ed., Monetary policy. Chicago: University of Chicago Press.

Mishkin, Frederic S., 1996. The channels of monetary transmission: lessons for monetary policy. Unpublished working paper. New York: Federal Reserve Bank of New York.

Morgan, Donald P., 1993. Asymmetric effects of monetary policy. Federal Reserve Bank of Kansas City Economic Review 2, 21-33.

Morgan, Donald P., forthcoming. The credit effects of monetary policy: Evidence using loan commitments. Journal of Money, Credit, and Banking.

Oliner, Stephen D. and Glenn D. Rudebusch, 1995. Is there a bank lending channel for monetary policy? Federal Reserve Bank of San Francisco Economic Review 2, 3-20.

Oliner, Stephen D. and Glenn D. Rudebusch, 1996. Is there a broad credit channel for monetary policy? Federal Reserve Bank of San Francisco Economic Review 1, 3-13.

Pagan, Adrian, 1986. Two stage and related estimators and their applications. Review of Economic Studies 53, 517-538.

Petersen, Mitchell A. and Raghuram G. Rajan, 1994. The benefits of lending relationships: Evidence from small business data. Journal of Finance 49(1), 3-37 (March).

Rajan, Raghuram G. and Luigi Zingales, 1995. The determinants of capital structure: Evidence from international data. Journal of Finance, 421-60.

Romer, Christina D. and David H. Romer, 1990. New evidence on the monetary transmission mechanism. Brookings Papers on Economic Activity 1, 149-98.

Slovin, M. B., M. E. Sushka, and J. A. Polonchek, 1993. The value of bank durability: Borrowers as bank stakeholders. Journal of Finance 48, 247-66 (March).

Stein, Jeremy C., 1995. An adverse selection model of bank asset and liability management with implications for the transmission of monetary policy. Working Paper No. 5217. Cambridge, MA: National Bureau of Economic Research (August).

Taylor, John B., 1995. The monetary transmission mechanism: an empirical framework. Journal of Economic Perspectives 9:4, 11-26 (Fall).

Worthington, Paula R., 1995. Investment, cash flow, and sunk costs. Journal of Industrial Economics 43:1, 49-61 (March). 


\section{A Mathematical Appendix}

\section{A.1 Derive the value of the bank's policy}

The optimal policy for this type of a problem is of the form $(u, \ell)$, where $u$ and $\ell$ are the bounds where infinitesimal regulation takes place. Inside the bounds, $z(t)$ is allowed to float freely. A proof that such a policy is optimal when the exogenous variables follow geometric Brownian motion can be found in Bertola (1988), chapter $1 .^{36}$ To determine the parameters of the optimal policy in the present model, I find the value of an arbitrary $(u, \ell)$ policy and then solve for the optimal $u$ and $\ell$. My presentation follows Dumas (1989), extended to the case of geometric Brownian motion.

Between the barriers $u$ and $\ell, z(t)$ follows

$$
\mathrm{d} z(t)=\mu_{z} z(t) \mathrm{d} t+\sigma_{z} z(t) \mathrm{d} w_{z}
$$

At $z=u$, a costless regulator is applied. At $z=\ell$, a costly regulator is applied. ${ }^{37}$

The value of an optimal program, given $u$ and $\ell$, is

$$
V(z(t))=\mathrm{E}_{t}\left[\int_{t}^{\infty} e^{-\rho(s-t)} f(z(s)) \mathrm{d} s-\Gamma\right]
$$

Assume $f(\cdot)$ is strictly concave and bounded. Rewrite (10) as a Bellman equation:

$$
\begin{aligned}
V(z(t))= & \max \left(\mathrm{E}_{t}\left[f(z(t)) \mathrm{d} t+e^{-\rho \mathrm{d} t} V(z(t+\mathrm{d} t))\right]\right. \\
& \left.\max _{\eta}(V(z+\eta)-\gamma 1(\eta>0) \eta)\right)
\end{aligned}
$$

$1(\cdot)$ is the indicator function. Remember that $0 \leq z(t) \leq 1$. Assume away the integer problem; the bank's control over $c(t)$ gives it perfect control over $z(t)$, allowing it to choose whatever increment or decrement $\eta$ it wants. When the bank chooses not to change the number of customers, (11) can

\footnotetext{
${ }^{36}$ Bertola's proof also requires the assumption $f^{\prime}>0, f^{\prime \prime}<0$.

${ }^{37} \mathrm{~A}$ more formal presentation can be found in Harrison (1985), defining the regulated process $z(t)$ by:

$$
\frac{z^{u r}(t) L(t)}{U(t)}
$$

where $\ell$ and $U$ are the lower and upper regulator processes and $z^{u r}$ is the path $z(t)$ would follow if unregulated. $\ell$ and $U$ are increasing and continuous. $L(0)=U(0)=1$. $U$ increases only when $z(t)=u$; $\ell$ increases when $z(t)=\ell$. I will follow the more intuitive presentation of Dumas, but the reader should keep in mind the rigorous foundation provided by Harrison.
} 
be rewritten as

$$
V(z(t))=f(z(t)) \mathrm{d} t+(1-\rho \mathrm{d} t)\left[V(z(t))+\mathrm{E}_{t} \mathrm{~d} V(z(t))\right]
$$

Using Ito's formula and (9),

$$
\mathrm{d} V=\left(\mu_{z} z V^{\prime}+\frac{\sigma_{z}^{2}}{2} z^{2} V^{\prime \prime}\right) \mathrm{d} t+\sigma_{z} z V^{\prime} \mathrm{d} w_{z}
$$

Take the expectation at time $t$ of (13), substitute into (12) and drop higher order terms to get

$$
\rho V(z)=f(z)+\mu_{z} z V^{\prime}+\frac{\sigma_{z}^{2}}{2} z^{2} V^{\prime \prime}
$$

Since costs of adjustment are purely proportional, $V$ will never take a discrete jump. The following "value-matching" conditions must hold:

$$
\begin{aligned}
& V^{\prime}(u)=0 \\
& V^{\prime}(\ell)=\gamma .
\end{aligned}
$$

These value-matching conditions ensure that the value function is continuous when an adjustment is made.

$V$ is the solution to the second order linear differential equation (14) with boundary conditions (15) and (16). ${ }^{38}$ Let $\bar{V}$ be a particular solution to (14). The general solution is

$$
\begin{aligned}
V(z) & =\bar{V}(z)+K_{1} z^{\delta_{1}}+K_{2} z^{\delta_{2}} \\
\text { where } \delta_{1} & =\frac{1}{2}\left[-\left(\frac{2 \mu_{z}}{\sigma_{z}^{2}}-1\right)+\sqrt{\left(\frac{2 \mu_{z}}{\sigma_{z}^{2}}-1\right)^{2}+\frac{8 \rho}{\sigma_{z}^{2}}}\right] \\
\delta_{2} & =\frac{1}{2}\left[-\left(\frac{2 \mu_{z}}{\sigma_{z}^{2}}-1\right)-\sqrt{\left(\frac{2 \mu_{z}}{\sigma_{z}^{2}}-1\right)^{2}+\frac{8 \rho}{\sigma_{z}^{2}}}\right] .
\end{aligned}
$$

If $\delta_{1}$ or $\delta_{2}$ is not a rational number, define $z^{\delta_{1}}$ as

$$
z^{\delta_{1}}=e^{\delta_{1} \ln z}
$$

\footnotetext{
${ }^{38}$ Dixit (1989) solves a similar equation.
} 
The constants $K_{1}$ and $K_{2}$ are pinned down by the boundary conditions (15) and (16). Without specifying a functional form for $f(\cdot),(17)$ is the most explicit solution feasible.

\section{A.2 Choose $u$ and $\ell$ optimally}

At $z=\ell$, infinitesimal adjustment must be optimal. Put another way,

$$
\begin{aligned}
\mathrm{d} z & =\arg \max _{\eta}(-\gamma \eta+V(\ell+\eta)) \\
\mathrm{FOC}: 0 & =-\gamma+V^{\prime}(\ell+\mathrm{d} z) \\
0 & =-\gamma+V^{\prime}(\ell)+V^{\prime \prime}(\ell) \mathrm{d} z \\
0 & =V^{\prime \prime}(\ell)
\end{aligned}
$$

and the last step uses (16). Equation (18) is the "smooth-pasting" condition for optimality. Since $V$ is known from (17), $\ell$ can be solved for. A similar argument applies to $u$. 